\title{
Shaping Electrocatalysis through Tailored Nanomaterials
}

\author{
Yijin Kang ${ }^{a}$, Peidong Yang ${ }^{b}$, Nenad M. Markovic ${ }^{c}$, Vojislav R. Stamenkovic ${ }^{c, *}$ \\ ${ }^{a}$ Institute of Fundamental and Frontier Sciences, University of Electronic Science and \\ Technology of China, Chengdu, China \\ ${ }^{\mathrm{b}}$ Department of Chemistry, University of California, Berkeley, CA 94720, United States \\ 'Materials Science Division, Argonne National Laboratory, 9700 Cass Ave, Argonne, IL 60439, \\ United States \\ * Corresponding author at: Division of Materials Science, Argonne National Laboratory, 9700 \\ Cass Ave, Argonne, IL 60439, United States. Tel.: +1 630-252-8946. E-mail address: \\ vrstamenkovic@anl.gov (V.R. Stamenkovic).
}

\begin{abstract}
:
Electrocatalysis is a subclass of heterogeneous catalysis that is aimed towards increase of the electrochemical reaction rates that are taking place at the surface of electrodes. Real-world electrocatalysts are usually based on precious metals in the form of nanoparticles due to their high surface-to-volume ratio, which enables better utilization of employed materials. Ability to tailor nanostructure of an electrocatalyst is critical in order to tune their electrocatalytic properties. Over the last decade, that has mainly been achieved through implementation of fundamental studies performed on well-defined extended surfaces with distinct single crystalline and polycrystalline structures. Based on these studies, it has been demonstrated that performance of an electrocatalyst could be significantly changed through the control of size, composition, morphology and architecture of employed nanomaterials. This review outlines the following steps in the process of rational development of an efficient electrocatalyst: 1) electrochemical properties of well-defined surfaces, 2) synthesis and characterization of different classes of electrocatalysts, and 3) correlation between physical properties (size, shape, composition and morphology) and electrochemical behavior (adsorption, electrocatalytic activity and durability) of electrocatalyst. In addition, this is a brief summary of the novel research platforms in the development of functional nanomaterials for energy conversion and storage applications such as fuel cells electrolyzers and batteries.
\end{abstract}

Keywords: Electrocatalysis; platinum alloys; surface modification 


\section{Introduction}

Profound understanding of electrochemical processes is closely connected to further advancement of technologies for energy conversion and storage, such as fuel cells[1-3], electrolyzers[4], and batteries[2]. Materials employed as electrodes in these applications have dual role: they serve as catalysts by lowering energy barrier for electrochemical reactions, and simultaneously, promote the electron charge transfer which takes place on the surfaces[5-11]. For that reason, the research focused on the well-defined surfaces under strictly controlled environments is considered as a valued approach in fundamental studies of electrochemical processes[6, 8, 9, 11-15]. The properties such as surface structure, composition and morphology are crucial to control along with electrochemical conditions in order to reveal structure-function relationship. The real-world electrocatalysts are usually made of costly precious metals in the form of nanoparticles which enables high utilization of employed materials [16-19]. For example, spherical nano-sized particles could have over 1000 times higher total surface area than their micro-sized counterparts of the same material and mass. However, nano-dimension brings complexity and opens many challenging questions that have to be addressed in order to characterize, apply and understand the influence of unique physical parameters such as lattice mismatch, defects, surface strain, low-coordinated atoms, etc.[20]. Consequently, rational approach in the design of catalyst requires isolation of targeted properties from each other for a nanoscale system of interest[21, 22]. For instance, in studies related to the particle size effect, the composition and morphology of material should be consistent for all samples[23]. Otherwise, it would be impossible to make reasonable conclusions about the relationship between physical characteristics and functional properties of nanoparticles. In what follows, we summarize the most recent progress in the research aimed to develop advanced nanoscale materials with properties that are tailored for specific electrochemical applications. 


\section{Well-defined surfaces and shape-controlled nanocrystals}

Different crystal planes are usually labeled with Miller indices that reflect arrangements of surface atoms, creating specific symmetries, and hence, specific adsorption sites[8, 9, 14, 24]. Each adsorption site on the very same surface exhibits distinct adsorption energy that has crucial role in determining the overall catalytic properties of the surface.
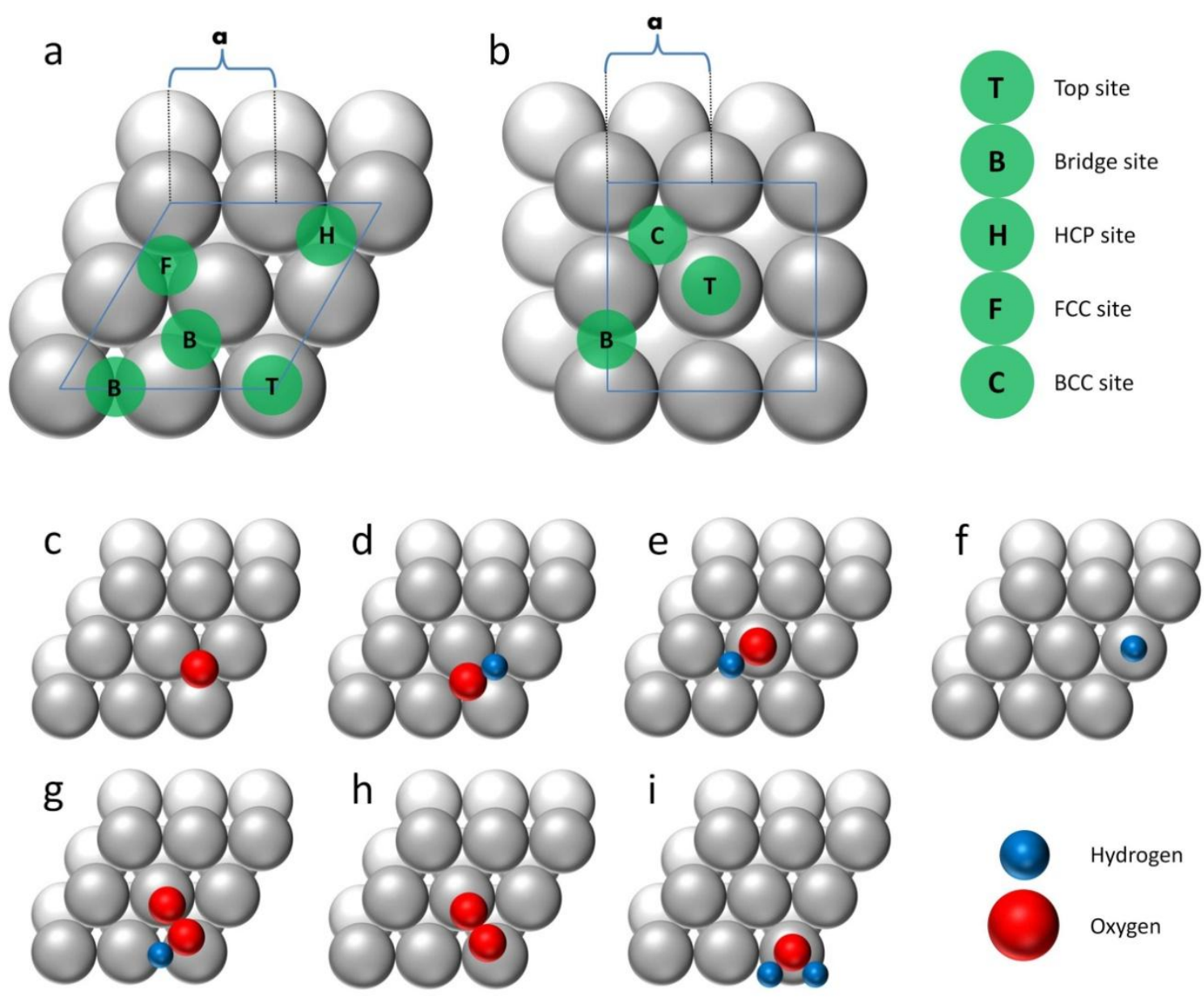

Figure 1. Atomic structures (top views) (a) (111) surface and (b) (100) surface. Various surface adsorption sites are marked, namely, top sites, bridge sites, HCP, FCC, and BCC sites. (c-i) Illustrations showing atomic structures of the typical geometries for adsorbed hydrogen and oxygen species on $\mathrm{Pt}(111)$ surface.

As shown in Figure 1, four different adsorption sites can be distinguished on (111) surface: top, bridge and two interstitial, namely face-centered cubic 
interstitial (FCC) and hexagonal close packed interstitial (HCP) sites; on the other (100) surface there are three adsorption sites: top, bridge and body-centered cubic interstitial (BCC). In the case of alloys, doped materials, or chemically modified surfaces, the symmetry may be more complex, generating additional adsorption sites. Figure $1 \mathrm{c}-\mathrm{i}$, depicts atomic structures on $\mathrm{Pt}(111)$ in typical adsorption geometries for oxygen and hydrogen species. For example, thermodynamically most favorable site for adsorption of atomic oxygen $\left(\mathrm{O}^{*}\right)$ would be interstitial site, while the bridge sites are preferred for oxygen molecules. The adsorption mechanism along with the energy of adsorption deviates among surface sites with different geometry, which can be used to distinguish active sites for certain catalytic processes. For instance, sulfate anions are strongly adsorbed on $\mathrm{Pt}(111)$ surface due to its three-fold symmetry which matches the one of sulfate anions, and hence, blocking the active sites for the ORR. Opposite to that, $\mathrm{Pt}(100)$ surface with a four-fold symmetry has alleviated sulfate adsorption, which leaves more Pt sites for adsorption of molecular oxygen, and therefore, exhibits higher activity than $\mathrm{Pt}(111)$ for the ORR in sulfuric acid $[25,26]$.

Structure sensitivity in electrocatalysis that is often referred as a structurefunction relationship which has been intensively studied on well-defined systems in the form of extended single- and poly-crystalline surfaces with known geometric surface area[6, 8, 14, 27]. Direct consequence of structural sensitivity is reflected at nanoscale as well-known particle size effect in electrocatalysis[23, 28]. However, it has to be emphasized that properties of single crystalline surfaces cannot be directly translated to nanomaterials due to the discrepancy between physical properties of extended- and nano-scale surfaces. For that reason, shape-controlled nanocrystals are getting ever increasing attention [20, 29-59].

Considering that platinum is the best single element electrocatalyst for the low temperature fuel cell reactions, the synthesis of Pt nanocrystals with controlled shape (including hollow Pt structure [60]) has been pursued by many research 
groups[20, 29-32, 35-37, 40, 42, 53, 61]. In general, thermodynamically favorable shape of chemically synthesized Pt nanocrystals is polyhedron with low-index plane (100), (110), and (111) surfaces. This is in accordance with the tendency of system to converge towards state with the minimum surface energy, also known as Wulff construction principle[62]. In order to obtain the excess of one or more specific facets by controlling the shape of nanocrystals, the growth of particle must be altered through the strategy that includes employment of reducing agent, activating or passivating particular crystal planes, and directing the growth by template or replacement. Among all the synthetic approaches, solution phase synthesis is the most common one due to possibility to tune a number of reaction parameters such as precursors, reducing agents, capping agents, solvents, additives, temperature, etc[63-65]. Representative examples of well-controlled synthesis of $\mathrm{Pt}$ nanocrystals are shown in Figure 2. Kang et al. synthesized monodisperse $\mathrm{Pt}$ nanocubes with exposed $\{100\}$ surfaces by reducing $\mathrm{Pt}$ acetylacetonate $\left[\mathrm{Pt}(\mathrm{acac})_{2}\right]$ with carbon monoxide, in the presence of oleylamine and oleic acid [55](Figure 2a). In addition, highly monodisperse Pt octahedra were synthesized in the presence of transition metal carbonyl, a bifunctional additive which decomposes to $\mathrm{CO}$ that provides reducing power, and transition metal (e.g. Fe, Co, Ni) with the role of shape-directing agent [53, 66](Figure 2b). Similar approach was used to prepare Pt octahedra, however, by careful tuning of reaction temperature and precursor-to-ligands ratio additional shapes were introduced such as icosahedra, truncated cubes, cuboctahedra, spheres, tetrapods, star-like octapods as well as multipods [66](Figure 2a-h, 2n-w); Huang et al. solvothermally prepared concaved star-like Pt nanocrystals by reduction of hexachloroplatinic acid $\left(\mathrm{H}_{2} \mathrm{PtCl}_{6}\right)$ in the presence of poly(vinylpyrrolidone) (PVP) and methylamine [67](Figure 2i); Yang and coworkers synthesized Pt tripods and multipods by using adamantanecarboxylic acid (ACA) and hexadecylamine (HDA) as capping agents in an organic solution phase synthesis (Figure $2 \mathrm{k}$, I)[37]; Wang and coworkers solvothermally synthesized Pt nanowires by reduction of hexachloroplatinic acid with ethylene glycol (EG) and N,Ndimethylmethanamide (DMF) [68](Figure 2m); Tilley and coworkers also obtained 
$\mathrm{Pt}$ nanocubes by reducing $\mathrm{Pt}(\mathrm{acac})_{2}$ in presence of oleylamine under a hydrogen pressure of 3 bar at $70{ }^{\circ} \mathrm{C}[41]$, while Lacroix et al. observed 5 -fold stars by reducing $\mathrm{H}_{2} \mathrm{PtCl}_{6}$ under 3 bar of hydrogen at $150{ }^{\circ} \mathrm{C}$ [69] (Figure 2j).

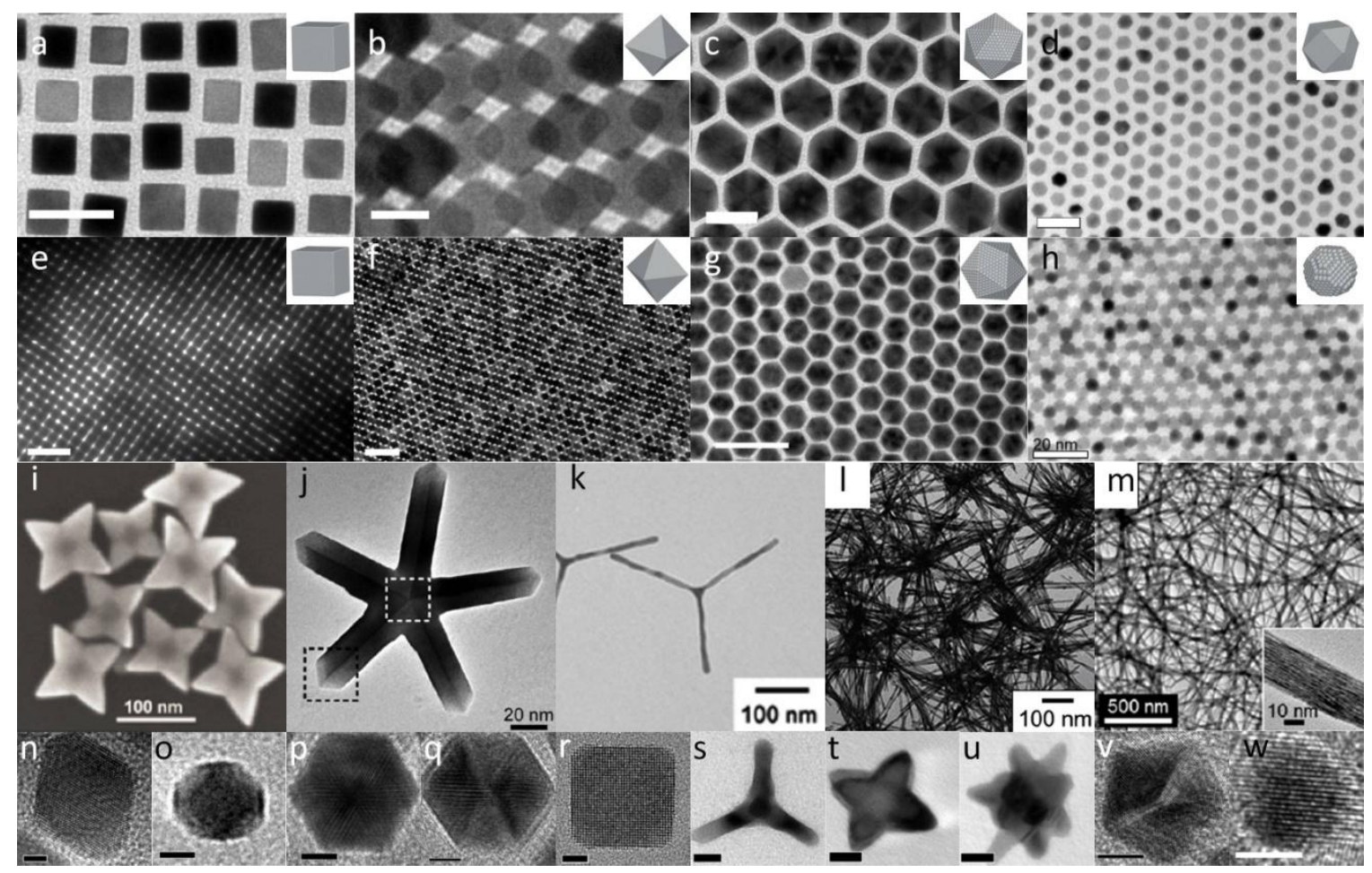

Figure 2. Pt nanocrystals with various shapes: (a, e, r) Pt cubes with $\{100\}$ surfaces, $(b, f, n) P t$ octahedral with $\{111\}$ surfaces, (c, g, p, q) Pt icosahedra with $\{111\}$ surfaces, (d, o) $P t$ cuboctahedra, (h, w) Pt spheres, (i, t) star-like octapods, (j) 5-fold star, (k) tripods, (l) hyperbranched multipods, (m) nanowires, (s) tetrapod, (u) multipod, (v) 5-fold twinned decahedron. Scale bars: (a, c, d, h, j) $20 \mathrm{~nm}$, (b, s, t, u) $10 \mathrm{~nm},(\mathrm{e}, \mathrm{f}, \mathrm{g}) 50 \mathrm{~nm},(\mathrm{i}, \mathrm{k}, \mathrm{l}) 100 \mathrm{~nm},(\mathrm{~m})$ $500 \mathrm{~nm},(\mathrm{n}, \mathrm{r}) 2 \mathrm{~nm},(\mathrm{o}, \mathrm{p}, \mathrm{q}, \mathrm{v}, \mathrm{w}) 5 \mathrm{~nm}$. (Modified with permissions from the American Chemical Society and WILEY $[41,53,67-69])$

Shape controlled nanocrystals are crucial in linking classic surface science and the real world nanoscale systems. As mentioned above, the ORR rate in nonadsorbing electrolytes $\left(0.1 \mathrm{M} \mathrm{HClO}_{4}, 0.1 \mathrm{M} \mathrm{KOH}\right)$ is higher on $\mathrm{Pt}(111)$ than on $\mathrm{Pt}(100)[8]$, while in the presence of sulfate ions $\left(0.1 \mathrm{M} \mathrm{H}_{2} \mathrm{SO}_{4}\right), \mathrm{Pt}(111)$ turns into the least active surface due to rather strong adsorption of sulfate anions that are preventing oxygen molecules to react with Pt surface atoms[26]. This finding can 
be translated to electrocatalytic properties of Pt nanocubes with exposed (100) facets. Indeed, the nanocubes exhibit higher ORR activity in sulfuric acid than particles with other surface geometries[46]. The other example reflects activities for formic acid oxidation on different $\mathrm{Pt}$ nanocrystals where $\mathrm{Pt}$ nanocubes perform better than Pt octahedra (i.e. \{111\})[53]. At the same time, Pt octahedra exhibit better poisoning tolerance at low oxidation potentials[53], which is consistent with the report on well-defined $\mathrm{Pt}(111)$ and $\mathrm{Pt}(100)$ surfaces by Adzic et al. in early 1980 's[14, 27]. In addition to surface orientation, defects are playing an important role in overall catalytic performance which additionally justifies validation of nanoscale systems by surface science approach in the course of design and synthesis of real-world electrocatalysts.
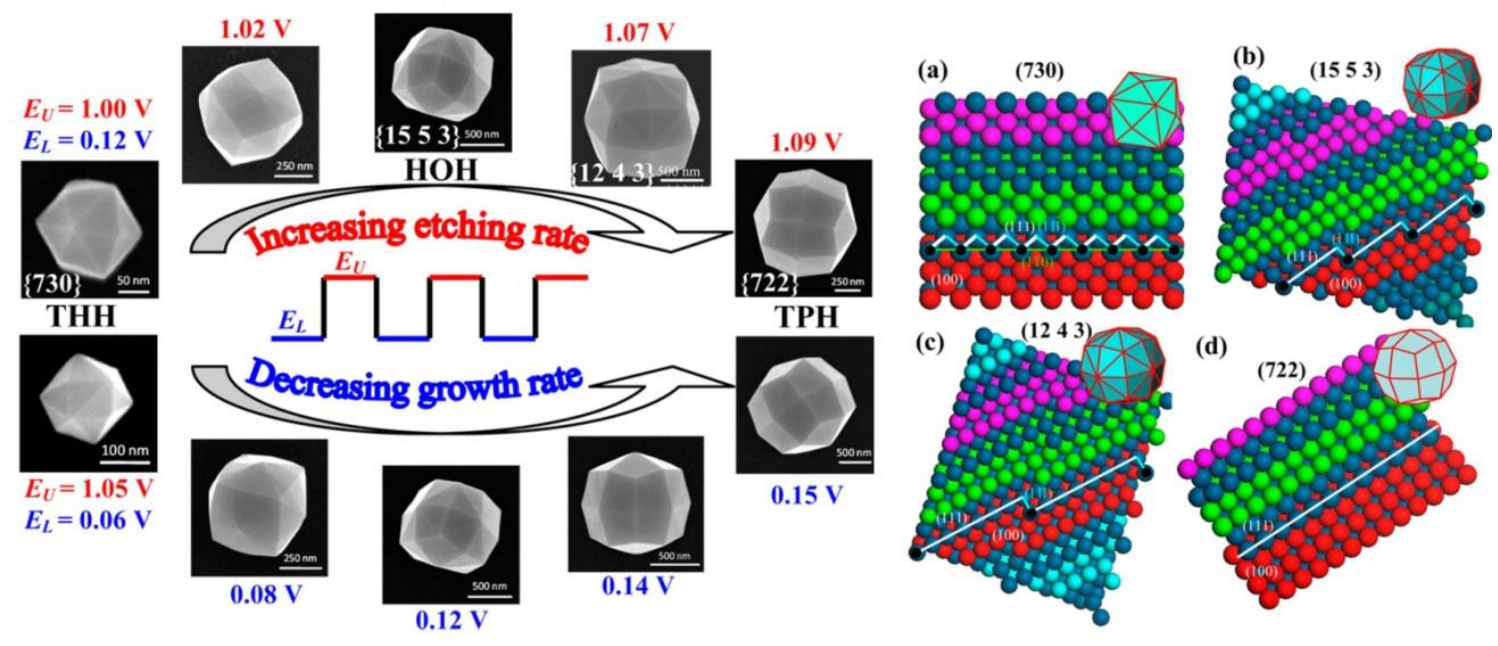

Figure 3. Preparation of Pt nanoparticles with high-index facets by electrochemical square-wave potential (SWP) method. Shape evolution of Pt nanocrystals from tetrahexahedron (THH) to trapezohedron $(\mathrm{TPH})$ via hexoctahedron $(\mathrm{HOH})$ is controlled by increasing the upper $\left(\mathrm{E}_{\mathrm{U}}\right)$ or lower potential $\left(E_{L}\right)$ of the SWP. The high-index facets: (a) (730), (b) (15 53 3), (c) (12 4 3), and (d) (722). (Modified with permission from the American Chemical Society [70])

Beyond low-index surfaces, the researchers have also been focused on highindex surfaces[67, 70-73]. Sun and coworkers developed the electrochemical square-wave potential method (SWP) that can be used to prepare high-index 
facets of $\mathrm{Pt}$ nanocrystals through the controlled growth and etching rate [71](Figure 3). Pt tetrahexahedra prepared by this method are enclosed by $\{730\}$, $\{210\}$, and/or $\{520\}$ surfaces that have rather high density of atomic steps which enabled superior catalytic activity towards electrooxidation of formic acid and ethanol. Same strategy was used to prepare hexoctahedron and trapezohedron which exposed other high-index surfaces, such as (15 5 3), (12 4 3), and (722), as shown in Figure 3 [70]. The concave star-like Pt nanocrystals shown in Figure 2i were claimed having $\{411\}$ facets[67], while Xia and coworkers reported concave Pt nanocubes in a similar shape, and those concave nanocubes were believed to consist $\{510\},\{720\}$ and $\{830\}$ facets[73]. Nevertheless, because $\mathrm{O}_{2}$ favorably adsorbs on steps which are abundant on high-index surfaces, concave Pt nanocubes exhibit superior ORR properties to Pt cubes and Pt/C catalysts.

\section{Composition-function relationship in electrocatalysis}

In addition to surface atomic structure and morphology of the catalyst, surface composition also has important role in determining overall performance[74-80]. For instance, dissociative adsorption of oxygen on catalyst surface is initial step in the oxygen reduction reaction, and therefore, a number of experimental and computational studies have been focused on fundamentals of oxygen adsorption mechanism[81]. The results are summarized in Figure $4 \mathrm{a}$, and it is important to mention that experimental studies conducted on Pt-alloys have been in good agreement with theoretical predictions[77, 78, 80, 82-85]. Combined results from our group and Nørskov and coworkers pointed towards connection between the ORR rate and the $d$-band structure of Pt-alloys[80, 81, 83, 86-89]. In acid electrolyte, adsorbed hydroxyl group, $\mathrm{OH}_{\mathrm{ad}}$, is a typical intermediate that inhibits $\mathrm{O}_{2}$ adsorption by blocking $\mathrm{Pt}$ sites[88]. For that reason, the optimal ORR activity counts on a fine balance between $\mathrm{O}_{2}$ and $\mathrm{OH}$ adsorption/desorption processes. A volcano type correlation for different metals between the adsorption strength of atomic oxygen and ORR activity is presented in Figure 4b. Binding energies for 
$\mathrm{O}$ and $\mathrm{OH}$ on $\mathrm{Pt}$ are optimal, which enables the highest turnover frequency, and hence, the highest ORR activity when compared to other metals. Importantly, the $\mathrm{Pt}$ is not located at the "summit of volcano", which indicates that further improvements should be feasible[81]. Such goal can be achieved by altering electronic properties of Pt based materials through alloying. In early studies on nanoscale systems Mukerjee and coworkers indicated that altered electronic properties of $\mathrm{Pt}$ are behind improved ORR activity of Pt-alloy catalysts[81]. Later studies on well-defined systems by our group as well as Kitchin et al. predicted that the surface properties of $\mathrm{Pt}$ can be altered by addition of $3 d$ transition metals[80]. Such systems were supposed to have modified electronic and thus adsorption properties based on calculated surface $d$-band density of states (Figure 4c). In subsequent studies by our group it has been experimentally confirmed that modification of surface electronic structure of $\mathrm{Pt}$ by $3 d$ transition metals effectively shifts $d$-band center, and while the level of enhancement of the ORR activity depends on alloying element[86-89]. At the same time, it has been identified that $\mathrm{Pt}_{3} \mathrm{Ni}$ and $\mathrm{Pt}_{3} \mathrm{Co}$ were the most active ORR electrocatalysts (Figure 4d)[84, 86-89]. In the case of studies on extended surfaces, we have used single- and poly-crystalline bulk materials as well as thin films of $\mathrm{Pt}_{3} \mathrm{M}(\mathrm{M}=\mathrm{Ti}, \mathrm{V}$, $\mathrm{Fe}, \mathrm{Co}, \mathrm{Ni}$ ) in conjunction with the surface specific tools to comprehensively explore structure-function relationships for the ORR[86-89]. Another approach in pursuing Pt based materials has been executed by Adzic and coworkers. They employed galvanic displacement of an underpotentially deposited $\mathrm{Cu}$ adlayer by $\mathrm{Pt}$ to generate a so called $\mathrm{Pt}$ monolayer catalysts over different metallic substrates (e.g. Ru, Ir, Rh, Au, Pd)[90, 91]. Casado-Rivera et al. used annealed powders of metals under high temperature to prepare ordered intermetallic compounds for fuel cell applications and particularly identified PtPb and PtBi as highly efficient methanol and formic acid oxidation electrocatalysts[92]. For electrocatalysts at nanoscale, the synthetic protocols which are used to prepare Pt nanocrystals are also valid to synthesize alloy and intermetallic nanoparticles. The synthetic method developed by Sun and Murray, which was originally used to prepare FePt nanocrystals[63], has been modified to synthesize various metal 
and metal alloy nanocrystals. Furthermore, Murray and co-workers synthesized shape controlled $\mathrm{Pt}_{3} \mathrm{Mn}$ [54], $\mathrm{Pt}_{3} \mathrm{Zn}$ [93], and $\mathrm{Pt}_{3} \mathrm{~Pb}$ [94] alloy and intermetallic nanocrystals and explored structure sensitivity of electrocatalysis. Fang and colleagues synthesized $\mathrm{Pt}_{3} \mathrm{Ni}$ nanocubes and octahedra, and found that $\mathrm{Pt}_{3} \mathrm{Ni}$ octahedra primarily enclosed by (111) facets exhibit higher ORR activity than $\mathrm{Pt}_{3} \mathrm{Ni}$ nanocubes[95], which was in good agreement with the observations made on extended surfaces[88]. Yang and coworkers extensively explored synthesis of $\mathrm{Pt}-\mathrm{Ni}$ nanoparticles[96-98], while Strasser's group investigated dealloyed electrocatalysts[99-101], and claimed the surface strain induced improvements of the ORR[102]. Sun and coworkers also intensively studied composition-property relationship for the ORR[103-107]. Due to the limited space, relatively small number of studies is featured in this review which reflects the main research directions in the ORR electrocatalysis[4, 60, 99-102, 108-119]. 

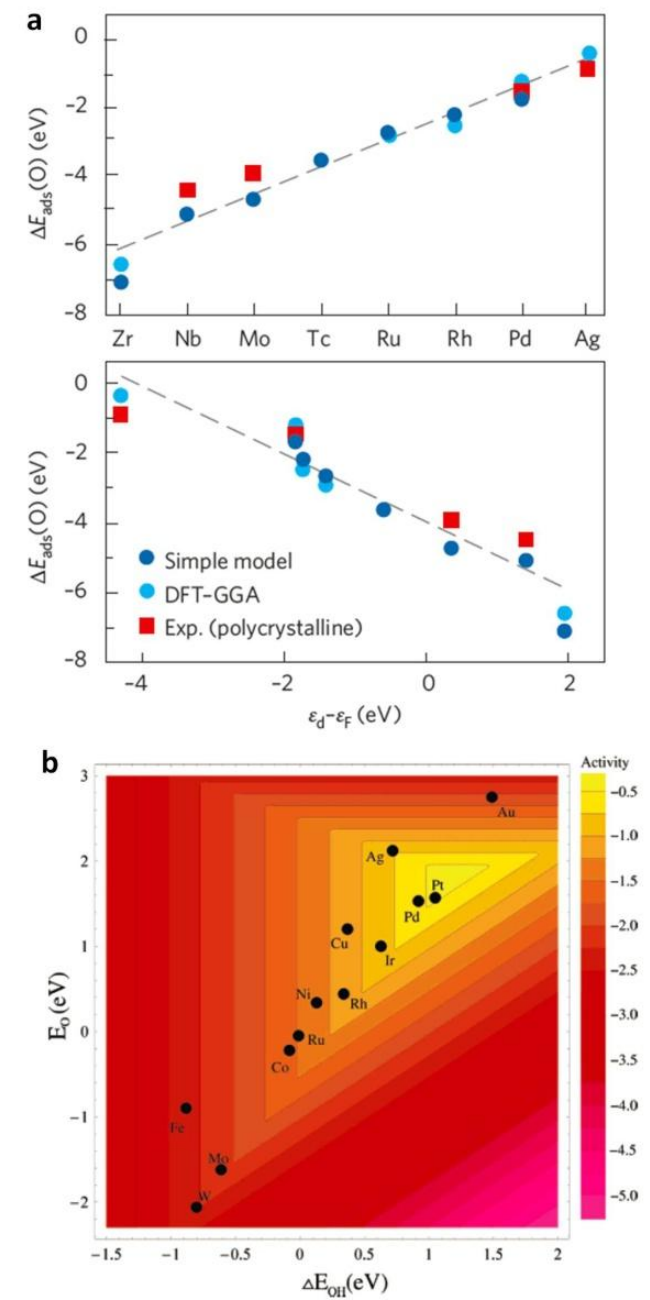
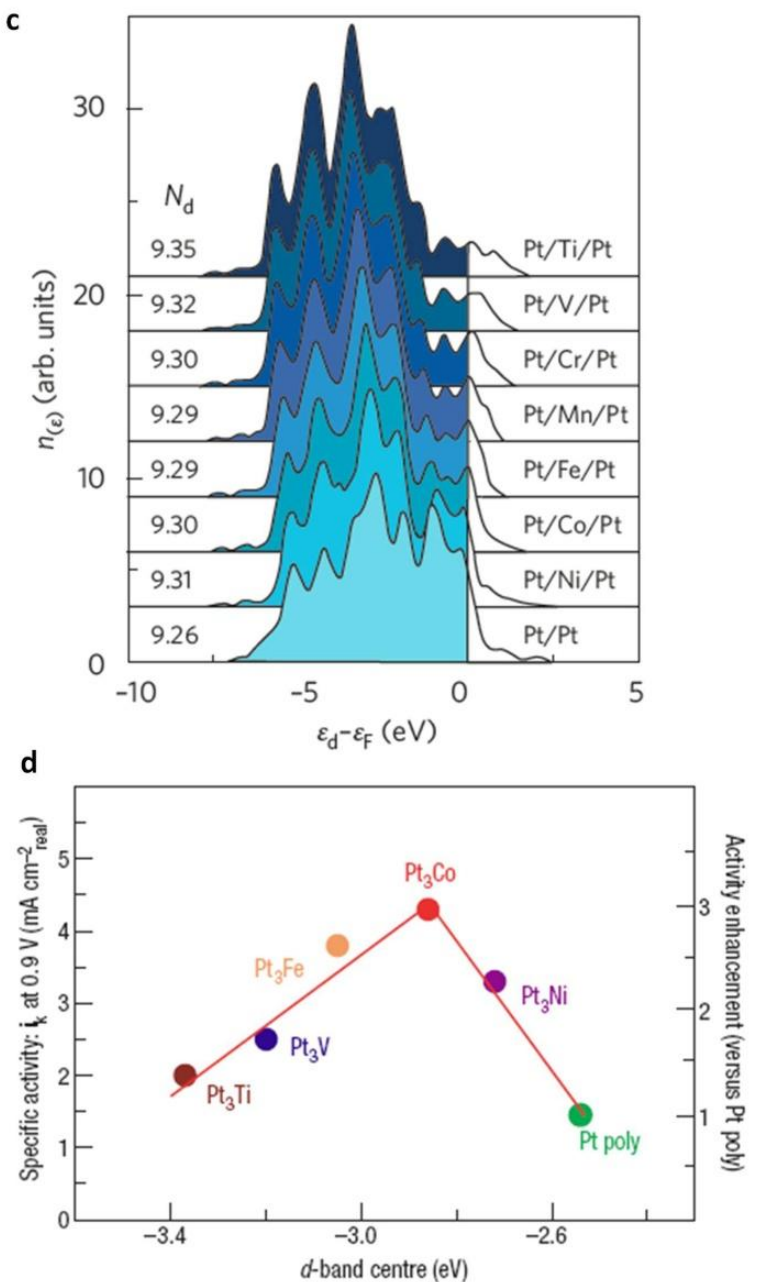

Figure 4. (a) Variations in the $O$ adsorption energy, $\Delta E_{\text {ads }}(O)$, on the most close-packed surface of the $4 d$ transition metal series. Below, the same data are plotted as a function of the average energy of the $d$-electrons (the $d$-band centre with respect to the Fermi level), $\varepsilon_{\mathrm{d}}-\varepsilon_{\mathrm{F}}$, on the transition metal. (b) Trends in ORR activity plotted as a function of both the $\mathrm{O}$ and the $\mathrm{OH}$ binding energy. (c) Modification of the surface electronic and chemical properties of $\mathrm{Pt}(111)$ by subsurface $3 d$ transition metals: calculated surface $d$-band density of state (DOS) for subsurface$3 d$-metal-containing Pt slabs. The number of $d$-electrons/surface atom is shown for each band. (d) Relationships between the catalytic properties and electronic structure of $\mathrm{Pt}_{3} \mathrm{M}$ alloys: experimentally measured specific activity for the ORR versus the $d$-band centre position for the Pt-skin surfaces. (Modified with permissions from the Nature Publishing Group and the American Chemical Society [80, 81, 85, 89]) 


\section{Design of high performance catalyst through tailoring the nanostructure}

In this section, we point out a general strategy to design high performance electrocatalyst for the ORR by incorporating beneficial properties of well-defined systems in a singular nanostructure.
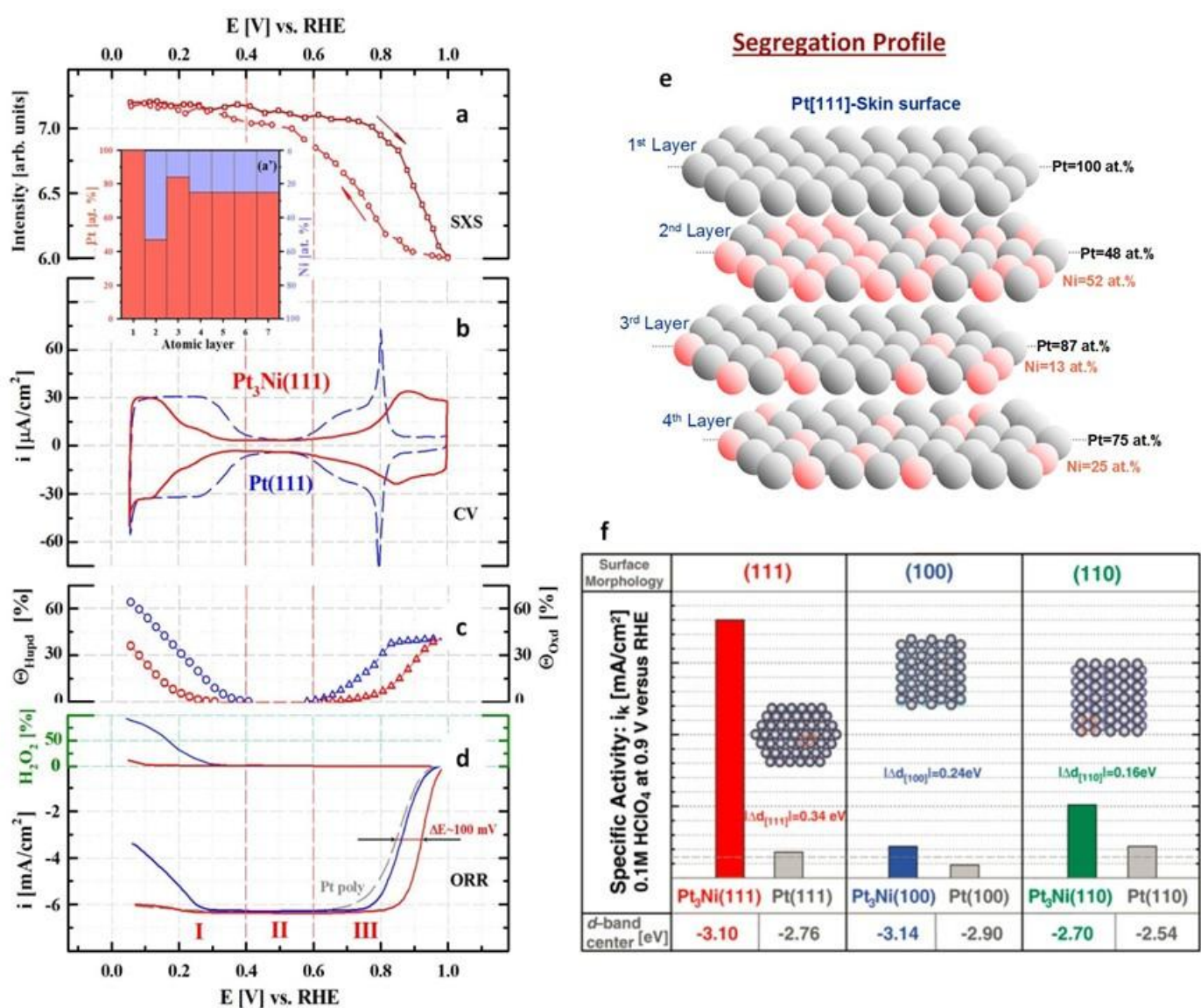

Figure 5. (a) Surface $x$-ray scattering (SXS) data and (inset) concentration profile revealed from SXS measurements. (b) Cyclic voltammograms, (c) surface coverage calculated from cyclic voltammograms, and d) polarization curves obtained from rotating ring disk electrode (RRDE) measurements. (e) Illustration of Pt-Skin profile. (f) Summary showing the influence of the surface morphology and electronic surface properties on the kinetics of ORR. (Modified with permission from the American Association for the Advancement of Science [88])

As discussed earlier, $\mathrm{Pt}$ is the most active element towards the ORR, and the activity can be further enhanced through alloying Pt with transition metals. Particularly, $\mathrm{Pt}_{3} \mathrm{M}(\mathrm{M}=\mathrm{Fe}, \mathrm{Co}$, and $\mathrm{Ni}$ ) are proven to be the most active 
composition by both experimental evidence and computational simulation[88, 89]. In our early work on well-defined single crystalline surfaces it has been found that $\mathrm{Pt}_{3} \mathrm{Ni}(111)$ exhibited much higher ORR activity than $\mathrm{Pt}_{3} \mathrm{Ni}(100)$ and $\mathrm{Pt}_{3} \mathrm{Ni}$ (110)[88]. Moreover, it was revealed that after annealing in vacuum $\mathrm{Pt}$ segregates over $\mathrm{Pt}_{3} \mathrm{Ni}$ and forms so called Pt-Skin surface [88](Figure 5). Based on this study, it was possible to identify three key factors responsible for high activity of the ORR: 1) $\mathrm{Pt}_{3} \mathrm{Ni}$ overall composition, 2) (111) surface structure, and 3) oscillatory compositional profile in the near surface region with the topmost $\mathrm{Pt}$ (111)-Skin formation which is electronically modified compared to $\mathrm{Pt}(111)$ system. In what followed, we have implemented these findings to develop practical materials. In attempt to mimic Pt-Skin formation in thin film catalysts, we have relied on so called nanostructured thin film (NSTF) systems developed by $3 M[120-122]$. A series of Pt-bimetallic thin film NSTF catalyst were made by magnetron sputtering over the perylene red substrate. It has been found that PtNi bimetallic NSTF exhibited the highest ORR activity when compared to other PtM alloys[122]. In order to explore how annealing process affects thin film catalysts we pursued an in-situ annealing approach by HRTEM. As depicted in Figure 6, annealing transforms the near surface region of Pt-Ni thin film into smooth (111)like Pt-Skin with so called mesostructured morphology (MSTF) (Figure 6, a-c). The PtNi MSTF shows a 20 -fold enhancement in the ORR activity over the stateof-the-art Pt/C electrocatalysts [122](Figure 6e). In addition to thin film materials, the approach in tuning compositional profile and surface morphology was extended to nanoparticles. Our effort to synthesize PtNi alloy nanoparticles was executed through reduction of $\mathrm{Pt}(\mathrm{acac})_{2}$ and nickel acetate $\left[\mathrm{Ni}(\mathrm{Ac})_{2}\right]$ by $1,2-$ tetradodecanediol in the presence of oleylamine and oleic acid[123]. Acid treatment turned PtNi alloy nanoparticles into PtNi nanoparticles with Pt-Skeleton surfaces, while the annealing protocol induced Pt segregation which has led to PtNi nanoparticles with unique multilayered Pt-Skin surfaces. An improvement factor for the ORR activity vs. Pt/C was found to be over 8 , which demonstrated that the approach of employing annealing to promote surface ordering and $\mathrm{Pt}$ segregation is also valid at nanoscale[123]. 


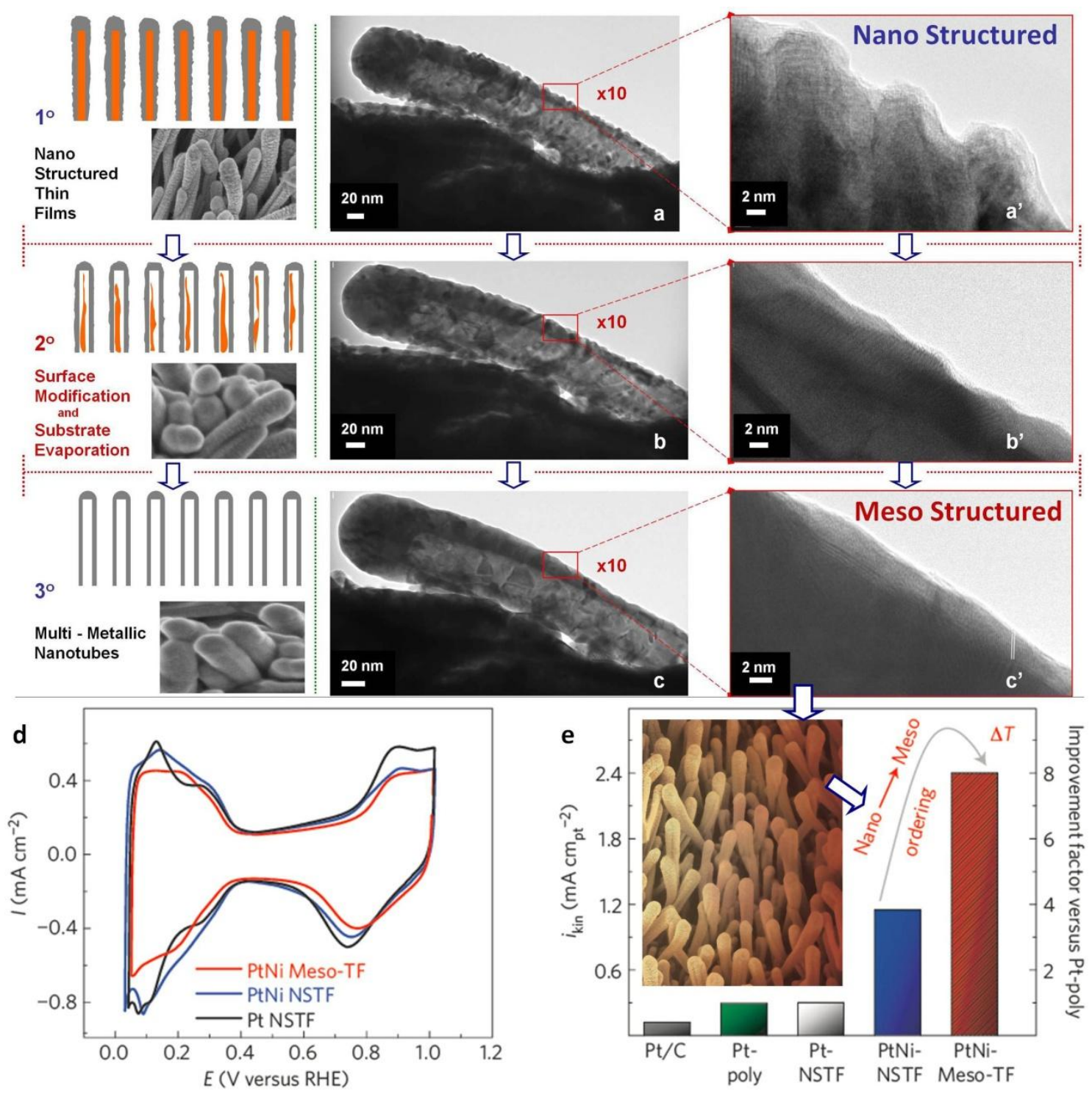

Figure 6. (a-c) In situ transformation from nanostructured into mesostructured thin film during annealing. d) Cyclic voltammograms of Pt-NSTF, PtNi-NSTF and PtNi-Meso-TF. e) Specific activities measured at $0.95 \mathrm{~V}$ and improvement factor versus Pt-poly. Inset of e) image of annealed mesostructured thin film which has the best ORR performance. (Modified with permission from the Nature Publishing Group [122])

Beyond composition profile and nanostructure, the local fine structure as well as additives may contribute to the overall performance of an electrocatalyst. Dealloying, a common corrosion process, is also an effective way to tailor electrocatalytic properties[99, 124]. Erlebacher and Sieradzki et al. carefully investigated the dealloying process of AuAg that generated porous gold (Figure 
7a-c), which is useful for many catalytic applications[124], e.g. selective oxidative coupling of methanol to methyl formate[125].

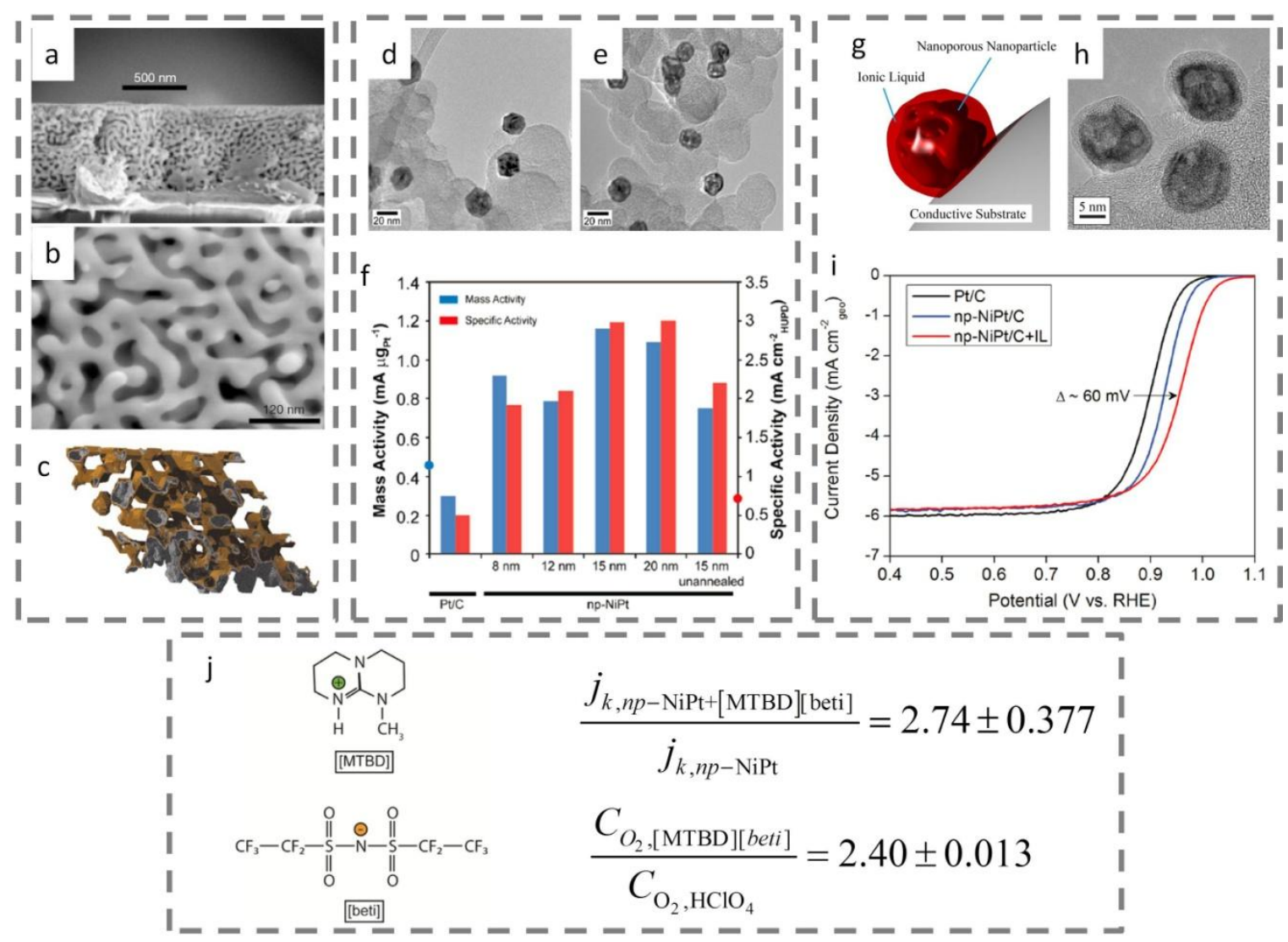

Figure 7. (a, b) SEM images and (c) simulated porous gold made by selective dissolution of silver from Ag-Au alloys immersed in nitric acid under free corrosion conditions. (d) Carbon supported $\mathrm{Ni}_{75} \mathrm{Pt}_{25}$ nanoparticles as-made and (e) annealed $\left(400{ }^{\circ} \mathrm{C}, \mathrm{H}_{2} / \mathrm{Ar}\right) /$ dealloyed nanoparticles (potential cycling from 0 to $1.2 \mathrm{~V}$ vs. $\mathrm{RHE}$ in deaerated $0.1 \mathrm{M} \mathrm{H}_{2} \mathrm{SO}_{4}$ at $25^{\circ} \mathrm{C}$ ). (f) Bar chart comparing mass (blue bars) and specific (red bars) activities (at $0.9 \mathrm{~V}$ ) of dealloyed $\mathrm{Ni} / \mathrm{Pt}$ nanoparticles to that of $\mathrm{Pt} / \mathrm{C}$ (30 wt\%, ETEK). (g) Illustration and (h) TEM image of porous NiPt nanoparticles encapsulated with (j) [MTBD][beti] ionic liquid (IL). (i) The ORR polarization curves of porous NiPt nanocatalysts with and without encapsulated IL, and commercial Pt/C catalysts. (j) The structure of [MTBD][beti] ionic liquid (IL), current density $\left(\mathrm{j}_{\mathrm{k}}\right)$ and oxygen concentration $\left(\mathrm{C}_{\mathrm{O}}\right)$. (Modified with permissions from the Nature Publishing Group, the American Chemical Society, and WILEY [124, 126-128])

The dealloying process creates nanoporosity and thus increases effective surface area of materials, which ultimately leads to high activity per unit mass of catalyst. For that reason, dealloying process has been adapted as an approach to prepare high performance electrocatalysts. For instance, Erlebacher and co- 
workers relied on free-corrosion (i.e. corrosion process without additional etching agent) to dealloy NiPt bimetallic nanoparticles (Figure 7d), producing highly porous NiPt nanostructures [126](Figure 7e). Because of high materials utilization (surface to volume ratio) that results from the porosity, the mass activity (for ORR) of these porous NiPt nanoparticles is almost four times of that $\mathrm{Pt} / \mathrm{C}$ electrocatalysts (Figure $7 \mathrm{f}$ ). In addition to higher surface area, highly porous materials can also be used on conjunction with ionic liquids. Snyder et al. discovered nanopores can successfully retain ionic liquid. Some ionic liquids( e.g. [MTBD][beti]) exhibit higher solubility for molecular oxygen if compared to a common electrolyte such as $\mathrm{HClO}_{4}$ [128](Figure 7j). That creates more favorable interface where oxygen is enriched at the surface of electrocatalyst, creating an engineered chemical bias that promotes completion of ORR. As shown in Figure $7 \mathrm{~g}$ and $7 \mathrm{~h}$, the protic ionic liquid is encapsulated in the pores of NiPt particles due to capillary force. The observed enhancement in the ORR activity matches the enhancement of oxygen solubility in ionic liquid [127, 128](Figure $7 \mathrm{i}$ and $7 \mathrm{j}$ ).

Based on the above examples it is possible to define strategy for designing high performance electrocatalysts for the ORR. The electrocatalyst should have high surface-to-volume ratio that enables optimal utilization of precious metals. The overall alloy composition between platinum and transition metal should be tuned around $\mathrm{Pt}_{3} \mathrm{M}$, which ensures optimal modification of electronic structure that leads towards suitable adsorption strength for reactants and intermediates. The topmost surface layer(s) should be pure Pt, so called Pt-Skin with (111)-like structure. That assumes the subsurface layers should be enriched in alloying component, which together with Pt-Skin surface creates nanosegregated compositional profile. Besides rather high surface to volume ratio in case of nanoparticles, there is still significant number of buried non-functional atoms of precious metal in the bulk of particle. This can be efficiently addressed by introducing highly porous particles or systems with an open frame architecture. Such structure can further improve material utilization and may enable addition of ionic liquids, which would have beneficial impact on the mass activity. At the first glance, it does seem difficult to have all the features in a single material. For 
instance, nanospheres may have high surface-to-volume ratio and desirable composition, however, it would not be feasible to have (111)-like surfaces due to the surface curvature. Another example are nanowires that have substantial extension of one dimension that allows (111) surface structure, nevertheless, the nanowires tend to bundle which compromises their surface-to-volume ratio and hence mass activity. Recently we have addressed this challenging task by introducing $\mathrm{Pt}_{3} \mathrm{Ni}$ nanoframe system, which successfully incorporated multiple beneficial properties in a single nanostructure[129, 130].
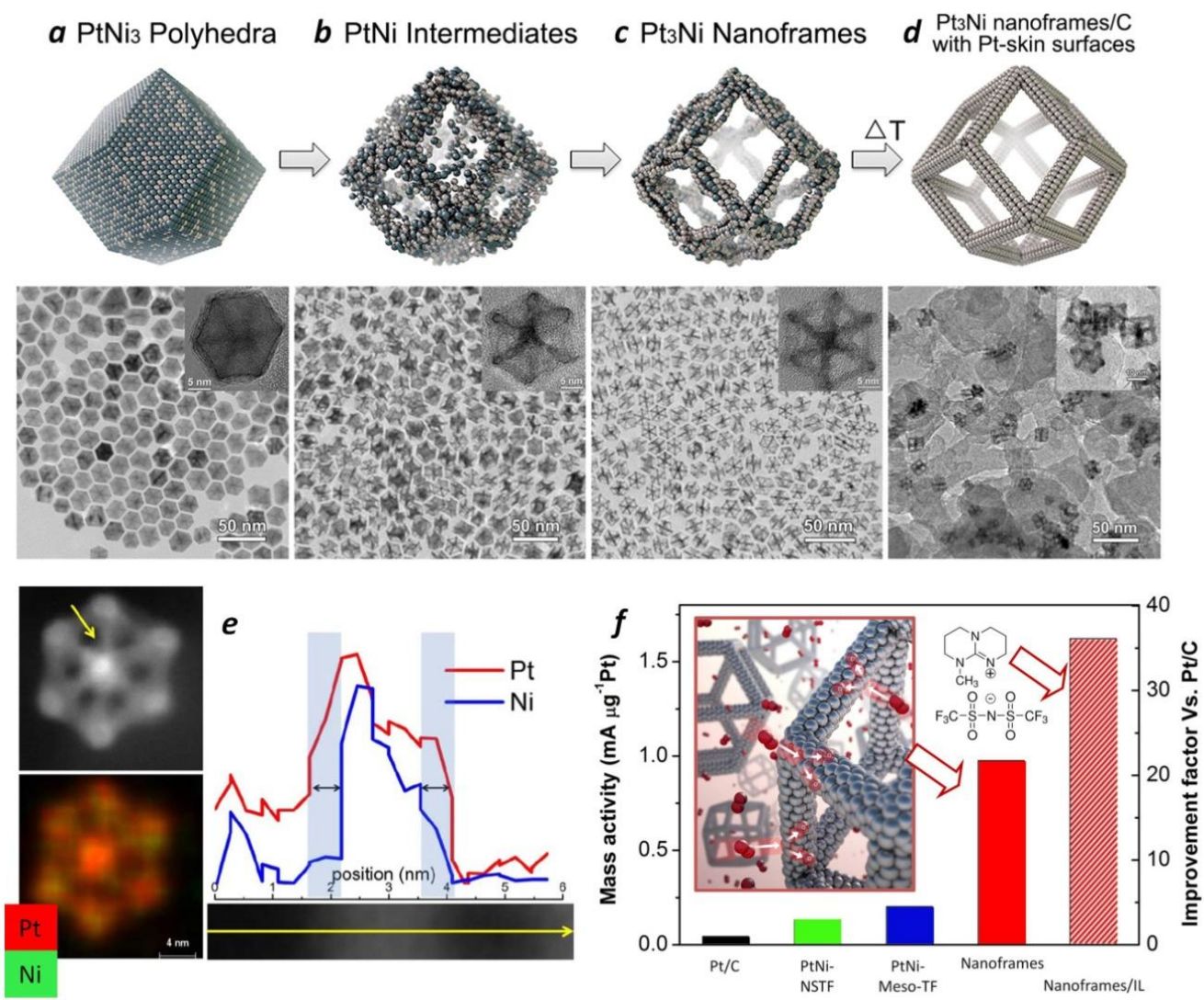

Figure 8. (a-d) Schematic illustrations and corresponding TEM images of the samples obtained at four representative stages during the evolution process from polyhedra to $\mathrm{Pt}_{3} \mathrm{Ni}$ nanoframes and annealed $\mathrm{Pt}_{3} \mathrm{Ni}$ nanoframes with $\mathrm{Pt}(111)$-Skin surfaces dispersed on high-surface area carbon. (e) EDX reveals that the thickness Pt-Skin is approximately 2 atomic layers. f) Bar chart comparing the mass activities $(0.95 \mathrm{~V})$ of $\mathrm{PtNi} N S T F$, Meso-TF, $\mathrm{Pt}_{3} \mathrm{Ni}$ nanoframes and ionic liquid (IL)-encapsulated $\mathrm{Pt}_{3} \mathrm{Ni}$ nanoframes to that of commercial $\mathrm{Pt} / \mathrm{C}$. (Modified with permission from the American Association for the Advancement of Science [129]) 
Through the process of free-corrosion, solid $\mathrm{PtNi}_{3}$ nanoparticles gradually evolve to hollow $\mathrm{Pt}_{3} \mathrm{Ni}$ nanoframes in the presence of oleylamine and oxygen [129](Figure 8 a-c). Upon annealing in the controlled environment, the surface of $\mathrm{Pt}_{3} \mathrm{Ni}$ nanoframes is being transformed into Pt-Skin structure (Figure 8d), with thickness of approximately two atomic layers, as revealed from EDX data [129](Figure 8e). These $\mathrm{Pt}_{3} \mathrm{Ni}$ nanostructures with well-defined parameters are essentially interconnected nanowires with a diameter of $2 \mathrm{~nm}$. The beneficial composition profile of $\mathrm{Pt}_{3} \mathrm{Ni}$-Pt Skin and the (111)-like surface morphology are combined with the open frame-like structure that enables three-dimensional accessibility of reactants to both internal and external surfaces. The $\mathrm{Pt}_{3} \mathrm{Ni}$ nanoframes exhibit over 20-fold enhancement in the ORR intrinsic (specific) activity over the state-of-the-art Pt/C electrocatalysts[129]. Moreover, the Pt-Skin and the frame structure render hydrophobic surface and strong capillary force that efficiently encapsulate ionic liquid with high oxygen-solubility and that further boosts the ORR activity to an unprecedented level of 36-fold enhancement vs. $\mathrm{Pt} / \mathrm{C}$ [129](Figure 8f). Since the nanoframes evolved to a thermodynamically stable $\mathrm{Pt}_{3} \mathrm{Ni}$ phase[131] and Pt-Skin surfaces protect underlayered materials from further leaching, the $\mathrm{Pt}_{3} \mathrm{Ni}$ nanoframes exhibit excellent stability, i.e. showing negligible activity loss over 10,000 cycles[129]. The porosity provided by framework is also the key to prevent washing-off of ionic liquid, even after extended operation of 10,000 cycles. An ORR activity map is presented in Figure 9, where different classes of Pt alloy electrocatalysts including nanoparticles dispersed on high-surface-area carbon, polycrystalline bulk materials and singlecrystalline alloys of $\mathrm{Pt}_{3} \mathrm{Ni}(111)$ surfaces are summarized[122, 129, 132]. This demonstrates how rational approach in tailoring properties of nanomaterials can make rather strong impact on electrocatalytic properties of practical materials which could potentially accommodate wide adoption of fuel cell technology[113, $114,129,133]$. 


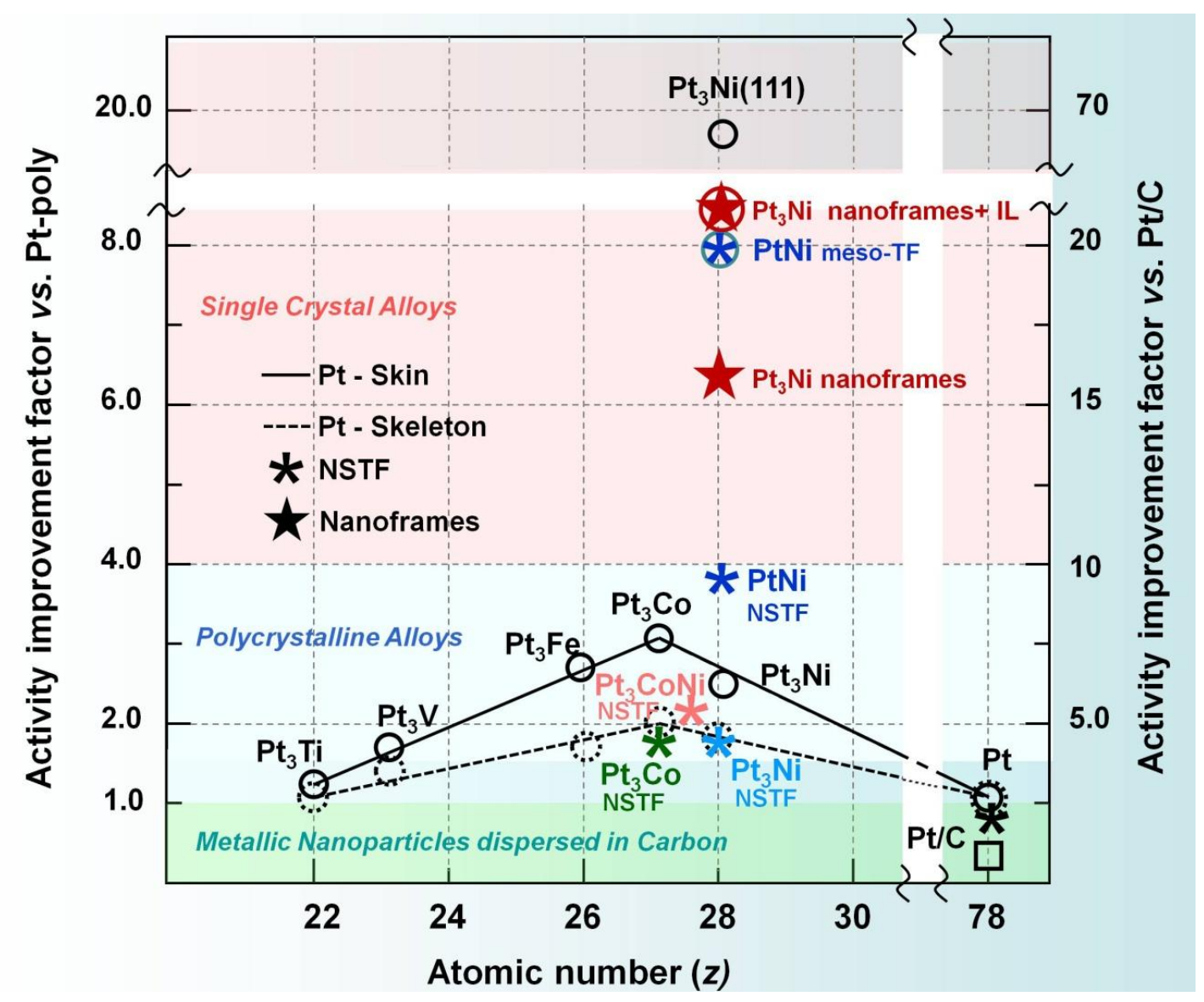

Figure 9. Activity map for the ORR for different classes of Pt-based materials. Improvement factors are given on the basis of specific activities compared with the values for polycrystalline $\mathrm{Pt}$ and the state-of-the-art $\mathrm{Pt} / \mathrm{C}$ catalyst established by $\mathrm{RDE}$ measurements in $0.1 \mathrm{M} \mathrm{HClO}_{4}$. (Modified with permission from the Nature Publishing Group [122])

\section{Tailoring Activity and Durability of Electrocatalysts}

Besides activity, it has been demonstrated that durability of an electrocatalyst can be tailored by manipulating the catalyst structure. Adzic and coworkers found that $\mathrm{Au}$ clusters deposited on $\mathrm{Pt} / \mathrm{C}$ electrocatalysts through a galvanic replacement of under-potentially deposited $\mathrm{Cu}$ monolayer could stabilize $\mathrm{Pt} / \mathrm{C}$ toward the ORR during 30,000 potential cycles[134]. Such durability enhancement was attributed to increased oxidation potential by surface $\mathrm{Au}$ atoms[134]. However, placing Au atoms on the surface causes a blocking effect towards Pt active sites. In order to address this issue, our group developed a 
core-shell electrocatalyst where an Au core was coated by a multilayered $\mathrm{FePt}_{3}$. Such core-shell $\mathrm{Au} / \mathrm{FePt}_{3}$ electrocatalysts showed negligible activity loss after 60,000 cycles between $0.6-1.1 \mathrm{~V}$ (vs. RHE)[135].
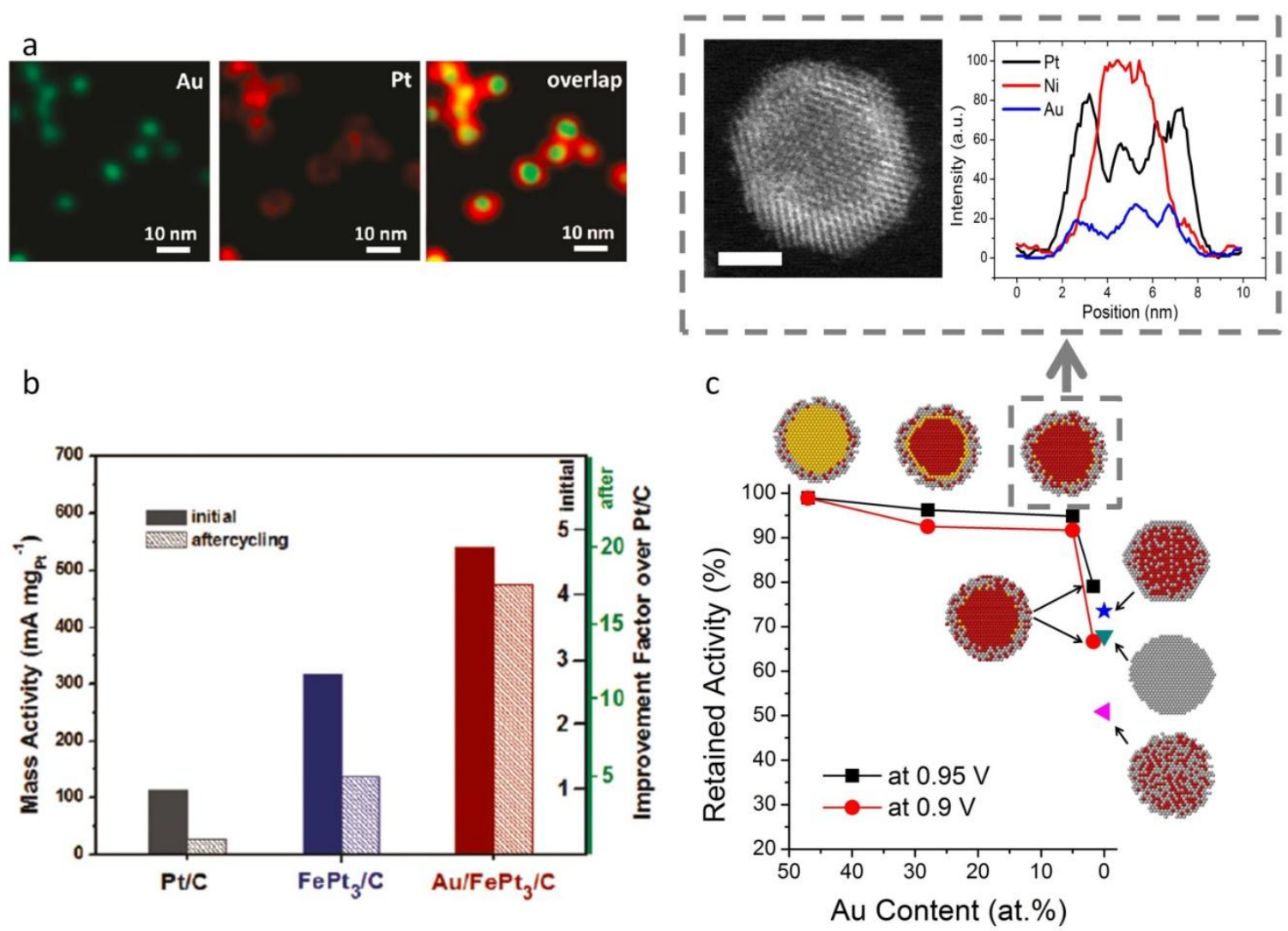

Figure 10. (a) EDX maps and (b) ORR performance (mass activity) of Au-FePt core-shell nanoparticles. Core-shell catalysts have extraordinary stability through disabling Pt dissolution via the place-exchange mechanism. c) Subsequent research and development further reduces the cost and improves the performance of ORR catalysts by employing a Ni-Au-PtNi core-sublayershell structure that minimizes utilization of precious metals and maximizes ORR activity while maintains the beneficial stabilization effect from the subsurface Au atoms. (Modified with permissions from the American Chemical Society [135, 136])

This exceptional durability was ascribed to the hindered place-exchange mechanism: surface oxygen atoms that readily move into the subsurface atomic layers promote dissolution of the surface Pt atoms[137]; however, this process is inhibited by underlayered $\mathrm{Au}$ atoms due to the weakened subsurface-Oadsorption caused by high oxidation potential of $A u$ atoms[135]. More recently, we evolved this approach by replacing Fe-Pt with Ni-Pt which is optimal for 
reactivity, and decreased the Au content to 5 at.\%[136] . Particularly, the $A u$ is used as an interlayer between rather inexpensive $\mathrm{Ni}$ core and the topmost bimetallic PtNi shell. Such Ni@Au@PtNi core/interlayer/shell structure possesses low cost due to minimized precious metal utilization, as well as optimal balance of activity and durability[136]. Similarly, Pt monolayer coated PdAu nanoparticles also exhibited great durability toward the ORR, however, with the enhanced durability attributed to that surface $\mathrm{Au}$ atoms occupied defect sites in the shell[138]. Nevertheless, all these cases demonstrated that activity, durability, and the fine balance between activity and durability can be tuned by tailoring the structure and composition of material. Another noteworthy example is given by Xia and co-workers who optimized and fine tuned overall composition of PtNi octahedrons[139]. In a more recent example published by the group from UCLA, the researchers synthesized PtNiMo octahedrons for which they claimed the highest activity along with durability[133].

\section{Tailoring Electrocatalysis through Surface Modification}

Surface modification is another effective avenue to tailor catalytic properties of an electrocatalyst. Our group reported a modification of Pt electrode surface by a controlled arrangement of $\mathrm{Ni}(\mathrm{OH})_{2}$ clusters for hydrogen evolution reaction (HER), where the edges of the $\mathrm{Ni}(\mathrm{OH})_{2}$ clusters facilitated the dissociation of $\mathrm{H}_{2} \mathrm{O}$ and the formation of $\mathrm{H}_{\mathrm{ad}}$ intermediates that are adsorbed on neighboring $\mathrm{Pt}$ atoms and then recombined into $\mathrm{H}_{2}$ [140](Figure 11). 

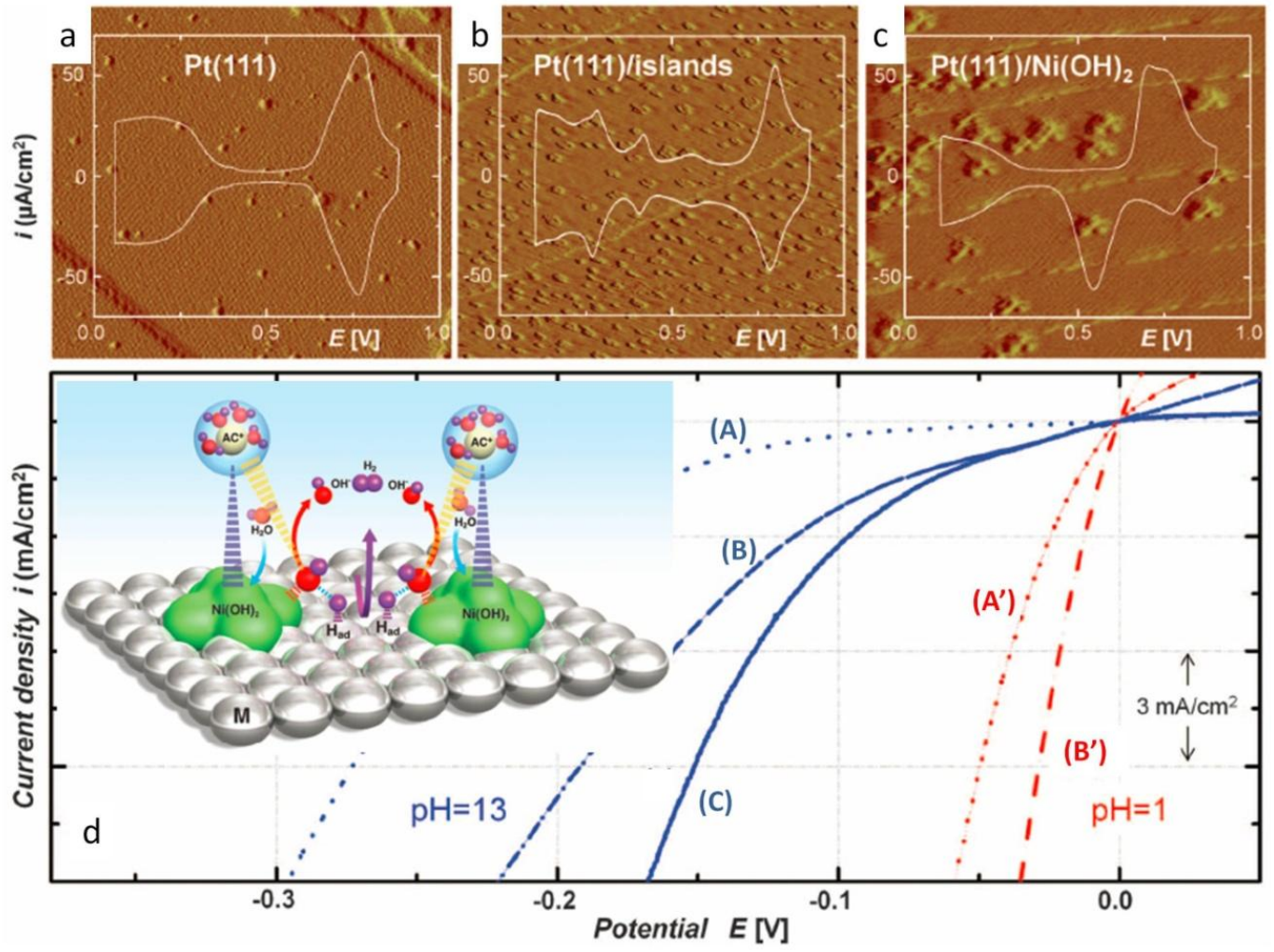

Figure 11. STM images (60 nm by $60 \mathrm{~nm}$ ) and CV traces for (a) Pt(111), (b) $\mathrm{Pt}(111)$ with 2D Pt islands, and (c) $\mathrm{Pt}(111)$ modified with $3 \mathrm{D} \mathrm{Ni}(\mathrm{OH})_{2}$ clusters in $0.1 \mathrm{M} \mathrm{KOH}$ electrolyte. (d) HER activities for $\mathrm{Pt}(111)$, $\mathrm{Pt}$-islands/Pt(111), and $\mathrm{Ni}(\mathrm{OH})_{2} / \mathrm{Pt}(111)$ surfaces in alkaline solution $(\mathrm{A}, \mathrm{B}$, and $C$, respectively). ( $A^{\prime}$ and $B^{\prime}$ ) Corresponding HER activities for $\mathrm{Pt}(111)$ and $\mathrm{Pt}$-islands/Pt(111) electrodes in acid solutions ( $V$ vs. RHE). The inset shows Schematic representation of water dissociation, formation of $\mathrm{M}-\mathrm{H}_{\mathrm{ad}}$ intermediates, and subsequent recombination of two $\mathrm{H}_{\mathrm{ad}}$ atoms to form $\mathrm{H}_{2}$ (magenta arrow) as well as $\mathrm{OH}$ - desorption from the $\mathrm{Ni}(\mathrm{OH})_{2}$ domains (red arrows) followed by adsorption of another water molecule on the same site (blue arrows). (Modified with permission from the American Association for the Advancement of Science [140])

With the bifunctional effect that was introduced by $\mathrm{Ni}(\mathrm{OH})_{2}$ clusters, modified $\mathrm{Pt}$ electrocatalysts showed an 8-fold enhancement in HER activity (at $\sim 120 \mathrm{mV}$ of overpotential), over the state-of-the-art metal and metal oxide electrocatalysts[140]. Chemical modification with small molecules has also been demonstrated as an effective way to tune catalytic properties. In another study by our group, Pt surface was modified by self-assembled monolayer of cyanides $\left(\mathrm{CN}^{-}\right)$which suppressed adsorption of sulfate and/or phosphate anions[141]. That has led to tremendous improvement of the ORR activity in so called strongly adsorbing electrolytes such as sulfuric and/or phosphoric acid (Figure 12). As 
mentioned above, $\mathrm{Pt}(111)$ surface exhibits lower ORR activity in these electrolytes due to specifically adsorbed anions (sulfate or phosphate anions) which match the surface symmetry and block the active sites for reactants. This is particularly the cause of the slow ORR rate in the phosphoric acid fuel cell, being the main limiting factor for wide application of this technology.

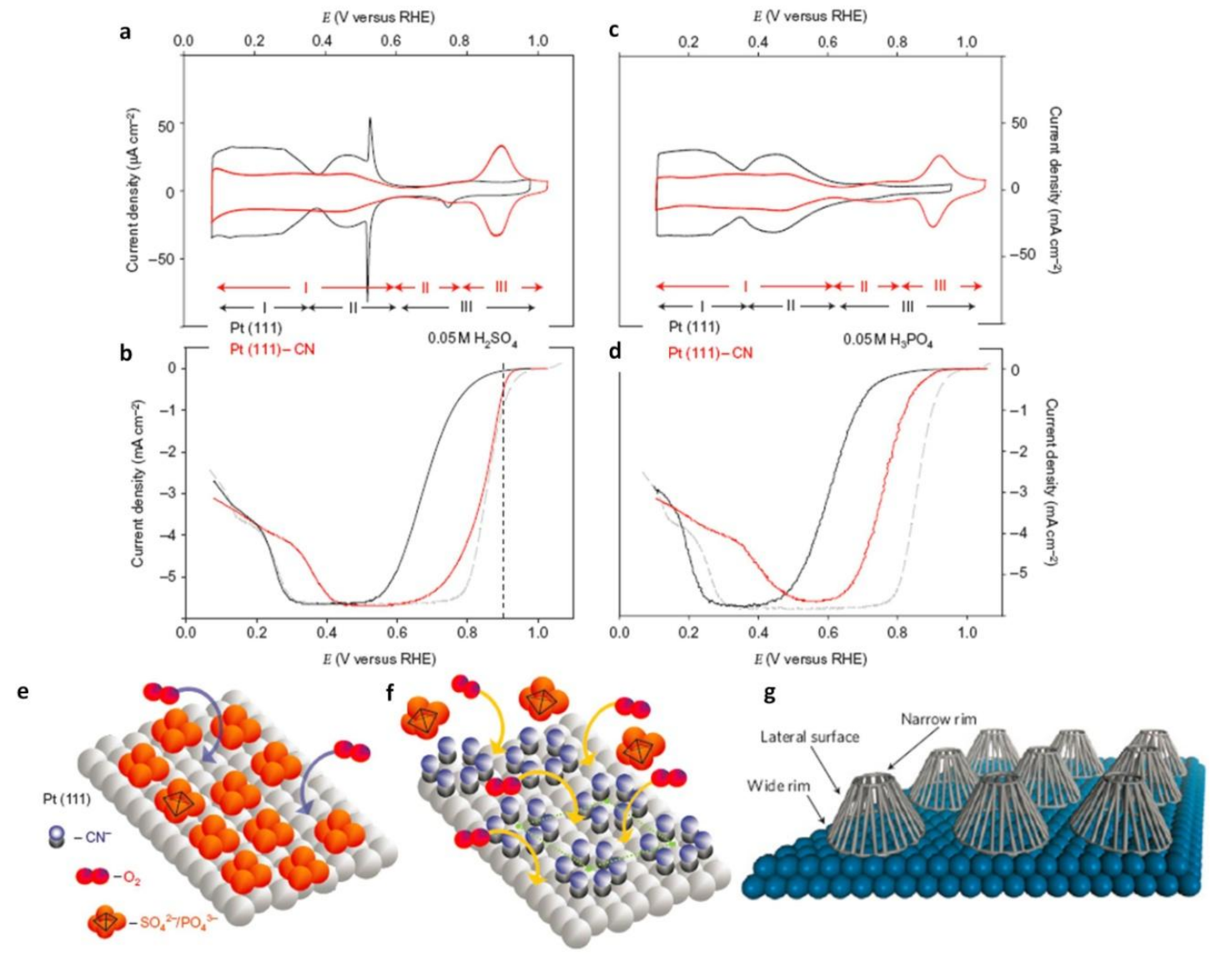

Figure 12. ( $a$ and $c$ ) Cyclic voltammograms and (b and d) ORR polarization curves of $\mathrm{CN}$ modified and unmodified $\mathrm{Pt}(111)$ surfaces in solutions containing strongly adsorbing ( $\mathrm{a}$ and $\mathrm{b}$ ) sulfuric and (c and d) phosphoric acid anions. Grey-dashed curves correspond to the ORR in 0.1 $\mathrm{M}$ perchloric acid. I, II and III designate the potential regions of $\mathrm{H}_{\text {upd }}$ adsorption, anion adsorption and $\mathrm{OH}$ adsorption, respectively. (e and f) Proposed models for selective adsorption of spectator species and reactants and schematic presentation of the availability of platinum surface atoms for adsorption of $\mathrm{O}_{2}$ molecules on $\mathrm{CN}$-free and $\mathrm{CN}$-covered $\mathrm{Pt}(111)$. (g) Schematic representation of calix[4]arene molecules attached to the $\mathrm{Pt}(111)$ surface via $-\mathrm{SH}$ groups located on the molecule's wide rim. (Modified with permissions from the Nature Publishing Group [141, 142]) 
Because of the bonding nature, $\sigma$-donation rather than by $\pi$-acceptor, $\mathrm{CN}^{-}$anions on the surface of $\mathrm{Pt}$ adapt the structure of hexagonal arrays, as shown in Figure 12f. The $\mathrm{CN}_{\mathrm{ad}}$ serves as a steric site-blocker, allowing $\mathrm{O}_{2}$ to react while disabling access of sulfate or phosphate anions to the surface[141]. Similar idea has been implemented to tune reaction selectivity: a self-assembled monolayer of calix[4]arene molecules behaves like a filter that allows the smaller $\mathrm{H}_{2}$ molecule to pass the narrow rim of calix[4]arene surface network while blocking the bigger $\mathrm{O}_{2}$ molecule[142]. That has led to selective fuel cell anode catalysts that can efficiently suppress the undesirable ORR while fully preserving desired activity for the hydrogen oxidation reaction (Figure 11g).

\section{Alternative approach in electrocatalysis: nanocrystal superstructure}

Well-controlled nanocrystal self-assemblies and other superstructures have been demonstrated as suitable tools for investigation of catalytic processes. Saltsburg et al. and Somorjai et al. fabricated layered microstructure and nanoparticles arrays, respectively, isolating various effects (e.g. size, morphology, support, interface and etc.) from each other in the course of catalysis studies[21, 143]. Yang and coworkers reported a multicomponent nanocrystal architecture as tandem catalyst that may even offer catalytic property which are not obtainable simply by mixing the same components[144]. Recently, the development in nanocrystal self-assembly allowed large-scale fabrication of multicomponent superlattices that combined the chemical and/or physical properties of different materials in a long-range ordered architecture, offering a unique opportunity to study synergistic interactions and collective properties[145-147]. As a result, nanocrystal superlattices were found particularly useful to investigate interfacial properties in the scope of catalysis research. Kang et al. demonstrated a fabrication of programmable $\mathrm{Au}-\mathrm{FeO}_{\mathrm{x}}$ interface by self-assembling $\mathrm{Au}$ and $\mathrm{FeO}_{x}$ nanocrystals into binary superlattices with various structures [146](Figure 13, ac). A linear correlationship between $\mathrm{CO}$ oxidation activity and number of $\mathrm{Au}-\mathrm{FeO}_{x}$ 
interfacial contacts revealed that the contacting $\mathrm{Au}$ and $\mathrm{FeO}_{\mathrm{x}}$ rather than the small sized Au nanoparticles could provide the highly active reaction sites[146] (Figure 13, $d$ and e). As a tool to probe interfacial synergistic effect for the ORR, Pt-Pd binary superlattices were recently fabricated [147](Figure 13, f-k).

$A B: 4$ interfaces / $A u$, $A B: 4$ interfaces / $\mathrm{FeO}_{x}$

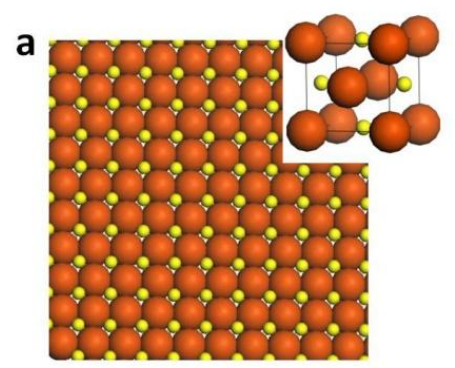

$A B_{2}: 3$ interfaces / Au $\quad A B_{13}: 2$ (of12) interfaces / $A u$ $A B_{2}: 6$ interfaces $/ \mathrm{FeO}_{x} \quad A B_{13}: 24$ interfaces $/ \mathrm{FeO}_{x}$

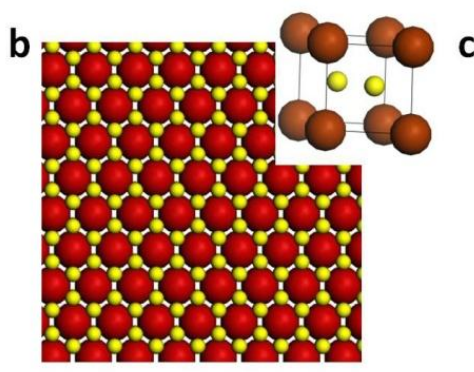

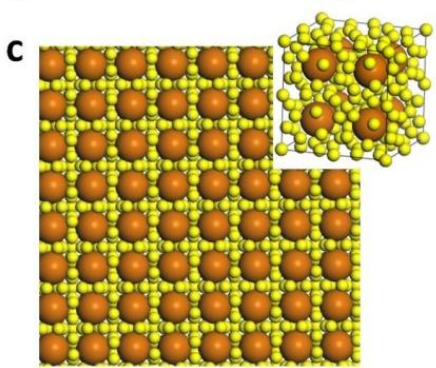
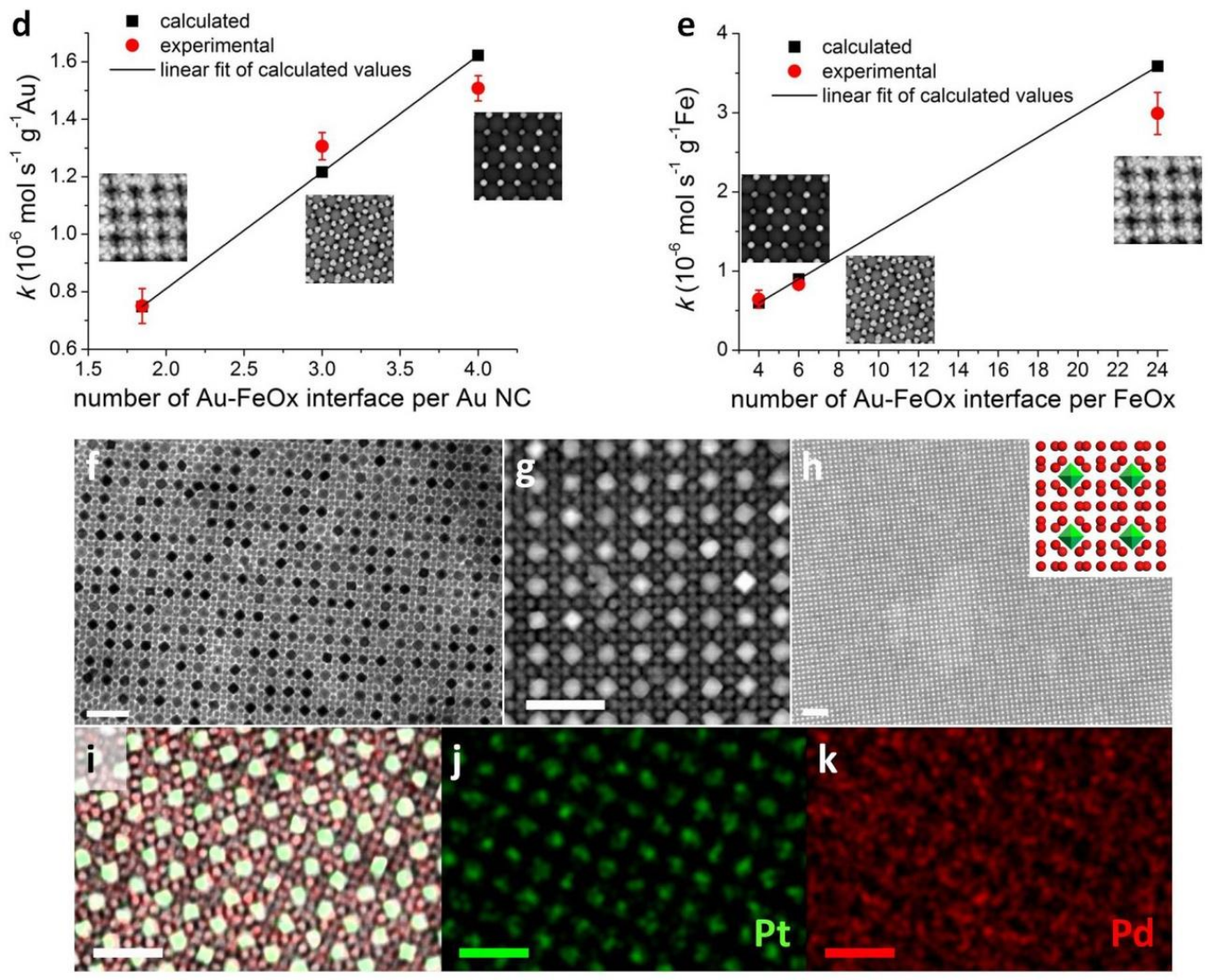

Figure 13. Nanocrystal superlattices that possess programmable contact interface provide a new research platform for catalysis studies. (a-c) Cartoons showing $\mathrm{Au}-\mathrm{FeO}_{\mathrm{x}}$ binary nanocrystal superlattices (BNSLs) in the structures of (a) $A B$ (CuAu analogue), (b) $A B_{2}$ ( $A_{1} B_{2}$ analogue), and (c) $A B_{13}\left(\mathrm{NaZn}_{13}\right.$ analogue). $\mathrm{CO}$ oxidation activity shows a linear correlationship to the number of $\mathrm{Au}-\mathrm{FeO}_{x}$ interface, (d) per Au nanocrystal and (e) per $\mathrm{FeO}_{x}$ nanocrystal, respectively. (f) TEM 
image, (g) STEM image, (h) SEM image, and (i-k) EDX maps of an $\mathrm{AB}_{13}$-type BNSL that consists of $\mathrm{Pd}$ nanoparticles and $\mathrm{Pt}$ octahedra. (Modified with permissions from the American Chemical Society $[146,147])$

It has been confirmed that nanocrystal superlattices and other superstructures are indeed useful model materials to explore, understand, and improve catalytic processes. As the selection of available components and structures increases[148], nano-superstructures are emerging as powerful new platform for research in the field of catalysis.

\section{Summary}

Great progress has been made over the last decade in the field of electrocatalysis[109, 110, 149-168]. For example, while the ORR activity has been substantially improved to the level that is acceptable for targeted technologies, the durability and cost still remain to be addressed. Challenges and opportunities may include following aspects:

1. Produce high performance electrocatalysts at large-scale. In current research and development $(R \& D)$ activities, electrocatalysts are prepared at milligram- or even microgram-level. Some scale-up attempts have been made to produce electrocatalysts at gram- or subgram-scale. As described earlier, most shape-controlled material synthesis are kinetically controlled, substantially limiting the reaction yield. Comparing to those thermodynamically controlled productions (e.g. to synthesize spherical, equilibrate iron oxides nanoparticles) that readily generate kilograms of materials, scale-up of shape-controlled catalysts while maintaining the desired performance is still challenging. 
2. Optimizing the balance between activity and durability. Neither a highly active but short-life catalyst nor stable material with low activity is desirable for real applicationss. Balance of activity and durability is crucial and remains one of the primary tasks of electrocatalyst development. For example, Pt-Skin is one origin to high ORR activity while Au atoms have the ability to stabilize surrounding $\mathrm{Pt}$ atoms through increasing oxidation potential and blocking place-exchange of oxygen; however, it seems impossible to have both features at the same time because currently the only way to generate Pt-Skin structure from near surface Pt-alloy is annealing, which also promotes migration of $\mathrm{Au}$ atoms to the top surface that is detrimental to ORR. At this moment in time, the high activity brought by Pt-Skin has to be compromised in order to utilize the Austabilization effect. In the future, with the development of materials science it may be possible to design the nanostructure that incorporates elements that feature both activity and durability.

3. Develop of low cost catalysts, e.g. non-platinum-group-metal (nonPGM). Although the performance of current non-PGM catalysts does not match that of Pt-based catalysts, disallowing the wide adoption of nonPGM at current stage, in the long run non-PGM may be one of only few viable options for industrial electrocatalysis, given the limitation in cost and reserve of PGM. Current non-PGM research covers metal oxides, carbon materials (carbon nanotubes, graphene, $\mathrm{N}$-doped carbon, etc.), carbides, borides, and etc. Continuously increasing non-PGM activity and improving the stability, especially in acidic environment, may enable a bright future for non-PGM catalysts.

4. Improving conductivity and stability of the support materials for electrocatalyst.

This review is aimed to bring the most recent progress and for that reason we have selected rather small number of representative examples that can 
effectively demonstrate how tailoring of the nanostructure can greatly affect electrocatalysis. As of now, it is apparent that so called rational approach is critical in developing next-generation of high performance materials for electrochemical applications, such as fuel cells, batteries, and electrolyzers. Although issues and challenges regarding stability, cost, scale-up, and activity are still to be addressed, there is no doubt that the rapid development in nanomaterials design is already shaping the future for sustainable energy technologies.

\section{Acknowledgement}

The research conducted at Argonne National Laboratory, was supported by the U.S. Department of Energy, Office of Science, Office of Basic Energy Sciences, Materials Sciences and Engineering Division, under Contract No. DE-AC02$06 \mathrm{CH} 11357$ and by the Office of Energy Efficiency and Renewable Energy, Fuel Cell Technologies Program. The portion of the research conducted at Lawrence Berkeley National Laboratory was supported by the U.S. Department of Energy, Office of Science, Office of Basic Energy Sciences, Materials Sciences and Engineering Division, under Contract No. DE-AC02-05CH11231. The authors thank to Chao Wang, Joshua Snyder, Dennis van der Vliet, Dusan Strmcnik, Dusan Tripkovic, Arvydas Paulikas, Jeffrey Greeley, Deborah Myers, Karren More and Philip Ross for many years of collaboration that has led to a number of publications in the field of electrocatalysis.

\section{References}

[1] S.M. Haile, Acta Mater., 51 (2003) 5981-6000.

[2] M. Winter, R.J. Brodd, Chem. Rev., 104 (2004) 4245-4269.

[3] M.K. Debe, Nature, 486 (2012) 43-51.

[4] R. Subbaraman, D. Tripkovic, K.-C. Chang, D. Strmcnik, A.P. Paulikas, P. Hirunsit, M. Chan, J. Greeley, V. Stamenkovic, N.M. Markovic, Nat. Mater., 11 (2012) 550-557.

[5] A.J. Appleby, Catal. Rev., 4 (1970) 221-222. 
[6] P.N. Ross, J. Electrochem. Soc., 126 (1979) 78-82.

[7] E. Yeager, Electrochim. Acta, 29 (1984) 1527-1537.

[8] N.M. Markovic, R.R. Adzic, B.D. Cahan, E.B. Yeager, J. Electroanal. Chem., 377 (1994) 249-

259.

[9] G.A. Somorjai, Chem. Rev., 96 (1996) 1223-1235.

[10] B.C.H. Steele, A. Heinzel, Nature, 414 (2001) 345-352.

[11] N.M. Markovic, P.N. Ross, Surf. Sci. Rep., 45 (2002) 121-229.

[12] J. Clavilier, C. Lamy, J.M. Leger, J. Electroanal. Chem., 125 (1981) 249-254.

[13] J. Clavilier, R. Parsons, R. Durand, C. Lamy, J.M. Leger, J. Electroanal. Chem., 124 (1981) 321-

326.

[14] R.R. Adzic, A.V. Tripkovic, W.E. Ogrady, Nature, 296 (1982) 137-138.

[15] N.M. Markovic, H.A. Gasteiger, P.N. Ross, X.D. Jiang, I. Villegas, M.J. Weaver, Electrochim. Acta, 40 (1995) 91-98.

[16] N. Mizuno, M. Misono, Chem. Rev., 98 (1998) 199-217.

[17] M. Valden, X. Lai, D.W. Goodman, Science, 281 (1998) 1647-1650.

[18] U.A. Paulus, A. Wokaun, G.G. Scherer, T.J. Schmidt, V. Stamenkovic, N.M. Markovic, P.N. Ross, Electrochim. Acta, 47 (2002) 3787-3798.

[19] U.A. Paulus, A. Wokaun, G.G. Scherer, T.J. Schmidt, V. Stamenkovic, V. Radmilovic, N.M. Markovic, P.N. Ross, J. Phys. Chem. B, 106 (2002) 4181-4191.

[20] Z.L. Wang, T.S. Ahmad, M.A. ElSayed, Surf. Sci., 380 (1997) 302-310.

[21] I. Zuburtikudis, H. Saltsburg, Science, 258 (1992) 1337-1339.

[22] P.L.J. Gunter, J.W. Niemantsverdriet, F.H. Ribeiro, G.A. Somorjai, Cat. Rev.-Sci. Eng., 39

(1997) 77-168.

[23] C. Wang, D. van der Vilet, K.-C. Chang, H. You, D. Strmcnik, J.A. Schlueter, N.M. Markovic, V.R. Stamenkovic, J. Phys. Chem. C, 113 (2009) 19365-19368.

[24] G.A. Somorjai, J. Carrazza, Ind. Eng. Chem. Fundam., 25 (1986) 63-69.

[25] J. Clavilier, R. Durand, G. Guinet, R. Faure, J. Electroanaly. Chem., 127 (1981) 281-287.

[26] N.M. Markovic, H.A. Gasteiger, P.N. Ross, J. Phys. Chem., 99 (1995) 3411-3415.

[27] R.R. Adzic, A.V. Tripkovic, N.M. Markovic, J. Electroanaly. Chem., 150 (1983) 79-88.

[28] K. Kinoshita, Electrochemical Oxygen Technology, WILEY1992.

[29] T.S. Ahmadi, Z.L. Wang, T.C. Green, A. Henglein, M.A. ElSayed, Science, 272 (1996) 19241926.

[30] T.S. Ahmadi, Z.L. Wang, A. Henglein, M.A. ElSayed, Chem. Mater., 8 (1996) 1161-\&.

[31] A. Rodriguez, C. Amiens, B. Chaudret, M.J. Casanove, P. Lecante, J.S. Bradley, Chem. Mater., 8 (1996) 1978-1986.

[32] R. Narayanan, M.A. El-Sayed, Nano Lett., 4 (2004) 1343-1348.

[33] Y.G. Sun, Y.N. Xia, Science, 298 (2002) 2176-2179.

[34] C. Burda, X.B. Chen, R. Narayanan, M.A. El-Sayed, Chem. Rev., 105 (2005) 1025-1102.

[35] H. Song, F. Kim, S. Connor, G.A. Somorjai, P.D. Yang, J. Phys. Chem. B, 109 (2005) 188-193.

[36] H. Lee, S.E. Habas, S. Kweskin, D. Butcher, G.A. Somorjai, P.D. Yang, Angew. Chem. Int. Ed., 45 (2006) 7824-7828.

[37] S. Maksimuk, X. Teng, H. Yang, Phys. Chem. Chem. Phys., 8 (2006) 4660-4663.

[38] K.M. Bratlie, H. Lee, K. Komvopoulos, P.D. Yang, G.A. Somorjai, Nano Lett., 7 (2007) 3097-

3101.

[39] S.E. Habas, H. Lee, V. Radmilovic, G.A. Somorjai, P. Yang, Nat. Mater., 6 (2007) 692-697.

[40] J. Ren, R.D. Tilley, Small, 3 (2007) 1508-1512.

[41] J.T. Ren, R.D. Tilley, J. Am. Chem. Soc., 129 (2007) 3287-3291.

[42] C. Wang, H. Daimon, Y. Lee, J. Kim, S. Sun, J. Am. Chem. Soc., 129 (2007) 6974-+. 
[43] Y.J. Xiong, Y.N. Xia, Adv. Mater., 19 (2007) 3385-3391.

[44] J. Solla-Gullon, F.J. Vidal-Iglesias, A. Lopez-Cudero, E. Garnier, J.M. Feliu, A. Aldaza, Phys.

Chem. Chem. Phys., 10 (2008) 3689-3698.

[45] A.R. Tao, S. Habas, P. Yang, Small, 4 (2008) 310-325.

[46] C. Wang, H. Daimon, T. Onodera, T. Koda, S.H. Sun, Angew. Chem. Int. Ed., 47 (2008) 3588-

3591.

[47] J. Chen, B. Lim, E.P. Lee, Y. Xia, Nano Today, 4 (2009) 81-95.

[48] I. Lee, F. Delbecq, R. Morales, M.A. Albiter, F. Zaera, Nat. Mater., 8 (2009) 132-138.

[49] Z. Peng, H. Yang, Nano Today, 4 (2009) 143-164.

[50] Y.N. Xia, Y.J. Xiong, B. Lim, S.E. Skrabalak, Angew. Chem. Int. Ed., 48 (2009) 60-103.

[51] T.K. Sau, A.L. Rogach, Adv. Mater., 22 (2010) 1781-1804.

[52] T.K. Sau, A.L. Rogach, F. Jaeckel, T.A. Klar, J. Feldmann, Adv. Mater., 22 (2010) 1805-1825.

[53] Y.J. Kang, M. Li, Y. Cai, M. Cargnello, R.E. Diaz, T.R. Gordon, N.L. Wieder, R.R. Adzic, R.J.

Gorte, E.A. Stach, C.B. Murray, J. Am. Chem. Soc., 135 (2013) 2741-2747.

[54] Y.J. Kang, C.B. Murray, J. Am. Chem. Soc., 132 (2010) 7568-7569.

[55] Y.J. Kang, X.C. Ye, C.B. Murray, Angew. Chem. Int. Ed., 49 (2010) 6156-6159.

[56] B. Wu, N. Zheng, Nano Today, 8 (2013) 168-197.

[57] G. Chen, Y. Tan, B. Wu, G. Fu, N. Zheng, Chem. Commun., 48 (2012) 2758-2760.

[58] M. Chen, B. Wu, J. Yang, N. Zheng, Adv. Mater., 24 (2012) 862-879.

[59] B. Wu, N. Zheng, G. Fu, Chem. Commun., 47 (2011) 1039-1041.

[60] J.X. Wang, C. Ma, Y.M. Choi, D. Su, Y.M. Zhu, P. Liu, R. Si, M.B. Vukmirovic, Y. Zhang, R.R.

Adzic, J. Am. Chem. Soc., 133 (2011) 13551-13557.

[61] S.I. Lim, I. Ojea-Jimenez, M. Varon, E. Casals, J. Arbiol, V. Puntes, Nano Lett., 10 (2010) 964973.

[62] G. Wulff, Zeitschrift Fur Krystallographie Und Mineralogie, 34 (1901) 449-530.

[63] S.H. Sun, C.B. Murray, D. Weller, L. Folks, A. Moser, Science, 287 (2000) 1989-1992.

[64] B.L. Cushing, V.L. Kolesnichenko, C.J. O'Connor, Chem. Rev., 104 (2004) 3893-3946.

[65] R.E. Schaak, A.K. Sra, B.M. Leonard, R.E. Cable, J.C. Bauer, Y.F. Han, J. Means, W. Teizer, Y.

Vasquez, E.S. Funck, J. Am. Chem. Soc., 127 (2005) 3506-3515.

[66] Y. Kang, J.B. Pyo, X. Ye, R.E. Diaz, T.R. Gordon, E.A. Stach, C.B. Murray, ACS Nano, 7 (2012)

645-653.

[67] X. Huang, Z. Zhao, J. Fan, Y. Tan, N. Zheng, J. Am. Chem. Soc., 133 (2011) 4718-4721.

[68] B.Y. Xia, H.B. Wu, Y. Yan, X.W. Lou, X. Wang, J. Am. Chem. Soc., 135 (2013) 9480-9485.

[69] L.-M. Lacroix, C. Gatel, R. Arenal, C. Garcia, S. Lachaize, T. Blon, B. Warot-Fonrose, E.

Snoeck, B. Chaudret, G. Viau, Angew. Chem. Int. Ed., 51 (2012) 4690-4694.

[70] J. Xiao, S. Liu, N. Tian, Z.-Y. Zhou, H.-X. Liu, B.-B. Xu, S.-G. Sun, J. Am. Chem. Soc., 135 (2013) 18754-18757.

[71] N. Tian, Z.Y. Zhou, S.G. Sun, Y. Ding, Z.L. Wang, Science, 316 (2007) 732-735.

[72] Y. Li, Y. Jiang, M. Chen, H. Liao, R. Huang, Z. Zhou, N. Tian, S. Chen, S. Sun, Chem. Commun., 48 (2012) 9531-9533.

[73] T. Yu, D.Y. Kim, H. Zhang, Y. Xia, Angew. Chem. Int. Ed., 50 (2011) 2773-2777.

[74] R.R. Adzic, D.N. Simic, A.R. Despic, D.M. Drazic, J. Electroanal. Chem., 65 (1975) 587-601.

[75] S. Motoo, M. Watanabe, J. Electroanal. Chem., 98 (1979) 203-211.

[76] M. Watanabe, Y. Furuuchi, S. Motoo, J. Electroanal. Chem., 191 (1985) 367-375.

[77] S. Mukerjee, S. Srinivasan, J. Electroanal. Chem., 357 (1993) 201-224.

[78] T. Toda, H. Igarashi, H. Uchida, M. Watanabe, J. Electrochem. Soc., 146 (1999) 3750-3756.

[79] J. Greeley, M. Mavrikakis, Nat. Mater., 3 (2004) 810-815.

[80] J.R. Kitchin, J.K. Norskov, M.A. Barteau, J.G. Chen,J. Chem. Phys., 120 (2004) 10240-10246. 
[81] J.K. Norskov, J. Rossmeisl, A. Logadottir, L. Lindqvist, J.R. Kitchin, T. Bligaard, H. Jonsson, The J. Phys. Chem. B, 108 (2004) 17886-17892.

[82] S. Mukerjee, S. Srinivasan, M.P. Soriaga, J. McBreen, J. Am. Chem. Soc., 142 (1995) 1409-

1422.

[83] N.M. Markovic, T.J. Schmidt, V. Stamenkovic, P.N. Ross, Fuel Cells, 1 (2001) 105-116.

[84] V. Stamenkovic, T.J. Schmidt, P.N. Ross, N.M. Markovic, J. Phys. Chem. B, 106 (2002) 1197011979.

[85] J.K. Norskov, T. Bligaard, J. Rossmeisl, C.H. Christensen, Nat. Chem., 1 (2009) 37-46.

[86] V. Stamenkovic, B.S. Mun, K.J.J. Mayrhofer, P.N. Ross, N.M. Markovic, J. Rossmeisl, J. Greeley, J.K. Norskov, Angew. Chem. Int. Ed., 45 (2006) 2897-2901.

[87] V.R. Stamenkovic, B.S. Mun, K.J.J. Mayrhofer, P.N. Ross, N.M. Markovic, J. Am. Chem. Soc., 128 (2006) 8813-8819.

[88] V.R. Stamenkovic, B. Fowler, B.S. Mun, G.F. Wang, P.N. Ross, C.A. Lucas, N.M. Markovic, Science, 315 (2007) 493-497.

[89] V.R. Stamenkovic, B.S. Mun, M. Arenz, K.J.J. Mayrhofer, C.A. Lucas, G.F. Wang, P.N. Ross, N.M. Markovic, Nat. Mater., 6 (2007) 241-247.

[90] J.L. Zhang, M.B. Vukmirovic, K. Sasaki, A.U. Nilekar, M. Mavrikakis, R.R. Adzic, J. Am. Chem. Soc., 127 (2005) 12480-12481.

[91] J.L. Zhang, M.B. Vukmirovic, Y. Xu, M. Mavrikakis, R.R. Adzic, Angew. Chem. Int. Ed., 44 (2005) 2132-2135.

[92] E. Casado-Rivera, D.J. Volpe, L. Alden, C. Lind, C. Downie, T. Vazquez-Alvarez, A.C.D. Angelo, F.J. DiSalvo, H.D. Abruna, J. Am. Chem. Soc., 126 (2004) 4043-4049.

[93] Y.J. Kang, J.B. Pyo, X. Ye, T.R. Gordon, C.B. Murray, ACS Nano, 6 (2012) 5642-5647.

[94] Y.J. Kang, L. Qi, M. Li, R.E. Diaz, D. Su, R.R. Adzic, E. Stach, J. Li, C.B. Murray, ACS Nano, 6 (2012) 2818-2825.

[95] J. Zhang, H. Yang, J. Fang, S. Zou, Nano Lett., 10 (2010) 638-644.

[96] J. Wu, J. Zhang, Z. Peng, S. Yang, F.T. Wagner, H. Yang, J. Am. Chem. Soc., 132 (2010) 4984+ .

[97] J. Wu, A. Gross, H. Yang, Nano Lett., 11 (2011) 798-802.

[98] J. Wu, L. Qi, H. You, A. Gross, J. Li, H. Yang, J. Am. Chem. Soc., 134 (2012) 11880-11883.

[99] S. Koh, P. Strasser, Journal of the American Chemical Society, 129 (2007) 12624-12625.

[100] C. Cui, L. Gan, M. Heggen, S. Rudi, P. Strasser, Nat. Mater., 12 (2013) 765-771.

[101] L. Gan, M. Heggen, R. O'Malley, B. Theobald, P. Strasser, Nano Lett., 13 (2013) 1131-1138.

[102] P. Strasser, S. Koh, T. Anniyev, J. Greeley, K. More, C. Yu, Z. Liu, S. Kaya, D. Nordlund, H.

Ogasawara, M.F. Toney, A. Nilsson, Nat. Chem., 2 (2010) 454-460.

[103] Q. Li, L. Wu, G. Wu, D. Su, H. Lv, S. Zhang, W. Zhu, A. Casimir, H. Zhu, A. Mendoza-Garcia, S. Sun, Nano Lett., 15 (2015) 2468-2473.

[104] S. Zhang, Y. Hao, D. Su, V.V.T. Doan-Nguyen, Y. Wu, J. Li, S. Sun, C.B. Murray, J. Am. Chem. Soc., 136 (2014) 15921-15924.

[105] S. Zhang, X. Zhang, G. Jiang, H. Zhu, S. Guo, D. Su, G. Lu, S. Sun, J. Am. Chem. Soc., 136 (2014) 7734-7739.

[106] D. Li, C. Wang, D.S. Strmcnik, D.V. Tripkovic, X. Sun, Y.J. Kang, M. Chi, J.D. Snyder, D. van der Vliet, Y. Tsai, V.R. Stamenkovic, S. Sun, N.M. Markovic, Energy Environ. Sci., 7 (2014) 40614069.

[107] S. Guo, D. Li, H. Zhu, S. Zhang, N.M. Markovic, V.R. Stamenkovic, S. Sun, Angew. Chem. Int. Ed., 52 (2013) 3465-3468.

[108] C. Cui, L. Gan, H.-H. Li, S.-H. Yu, M. Heggen, P. Strasser, Nano Lett., 12 (2012) 5885-5889.

[109] C. Wang, N.M. Markovic, V.R. Stamenkovic, ACS Catal., 2 (2012) 891-898. 
[110] S.-I. Choi, S. Xie, M. Shao, J.H. Odell, N. Lu, H.-C. Peng, L. Protsailo, S. Guerrero, J. Park, X. Xia, J. Wang, M.J. Kim, Y. Xia, Nano Lett., 13 (2013) 3420-3425.

[111] D. Wang, H.L. Xin, R. Hovden, H. Wang, Y. Yu, D.A. Muller, F.J. DiSalvo, H.D. Abruna, Nat. Mater., 12 (2013) 81-87.

[112] S. Xie, S.-I. Choi, N. Lu, L.T. Roling, J.A. Herron, L. Zhang, J. Park, J. Wang, M.J. Kim, Z. Xie, M. Mavrikakis, Y. Xia, Nano Lett., 14 (2014) 3570-3576.

[113] L. Zhang, L.T. Roling, X. Wang, M. Vara, M. Chi, J. Liu, S.-I. Choi, J. Park, J.A. Herron, Z. Xie, M. Mavrikakis, Y. Xia, Science, 349 (2015) 412-416.

[114] L. Gan, C. Cui, M. Heggen, F. Dionigi, S. Rudi, P. Strasser, Science, 346 (2014) 1502-1506.

[115] Y.-C. Hsieh, Y. Zhang, D. Su, V. Volkov, R. Si, L. Wu, Y. Zhu, W. An, P. Liu, P. He, S. Ye, R.R.

Adzic, J.X. Wang, Nat. Commun., 4 (2013) 2466.

[116] A.U. Nilekar, K. Sasaki, C.A. Farberow, R.R. Adzic, M. Mavrikakis, J. Am. Chem. Soc., 133

(2011) 18574-18576.

[117] K. Sasaki, H. Naohara, Y. Cai, Y.M. Choi, P. Liu, M.B. Vukmirovic, J.X. Wang, R.R. Adzic, Angew. Chem. Int. Ed., 49 (2010) 8602-8607.

[118] J.X. Wang, H. Inada, L.J. Wu, Y.M. Zhu, Y.M. Choi, P. Liu, W.P. Zhou, R.R. Adzic, J. Am. Chem. Soc., 131 (2009) 17298-17302.

[119] D.F. van der Vliet, C. Wang, D. Li, A.P. Paulikas, J. Greeley, R.B. Rankin, D. Strmcnik, D. Tripkovic, N.M. Markovic, V.R. Stamenkovic, Angew. Chem. Int. Ed., 124 (2012) 3193-3196. [120] D. van der Vliet, C. Wang, M. Debe, R. Atanasoski, N.M. Markovic, V.R. Stamenkovic, Electrochim. Acta, 56 (2011) 8695-8699.

[121] M.K. Debe, A.K. Schmoeckel, G.D. Vernstrorn, R. Atanasoski, J. Power Sources, 161 (2006) 1002-1011.

[122] D.F. van der Vliet, C. Wang, D. Tripkovic, D. Strmcnik, X.F. Zhang, M.K. Debe, R.T. Atanasoski, N.M. Markovic, V.R. Stamenkovic, Nat. Mater., 11 (2012) 1051-1058.

[123] C. Wang, M. Chi, D. Li, D. Strmcnik, D. van der Vliet, G. Wang, V. Komanicky, K.-C. Chang, A.P. Paulikas, D. Tripkovic, J. Pearson, K.L. More, N.M. Markovic, V.R. Stamenkovic, J. Am. Chem. Soc., 133 (2011) 14396-14403.

[124] J. Erlebacher, M.J. Aziz, A. Karma, N. Dimitrov, K. Sieradzki, Nature, 410 (2001) 450-453.

[125] A. Wittstock, V. Zielasek, J. Biener, C.M. Friend, M. Baeumer, Science, 327 (2010) 319-322.

[126] J. Snyder, I. McCue, K. Livi, J. Erlebacher, J. Am. Chem. Soc., 134 (2012) 8633-8645.

[127] J. Snyder, K. Livi, J. Erlebacher, Adv. Funct. Mater., 23 (2013) 5494-5501.

[128] J. Snyder, T. Fujita, M.W. Chen, J. Erlebacher, Nat. Mater., 9 (2010) 904-907.

[129] C. Chen, Y. Kang, Z. Huo, Z. Zhu, W. Huang, H.L. Xin, J.D. Snyder, D. Li, J.A. Herron, M.

Mavrikakis, M. Chi, K.L. More, Y. Li, N.M. Markovic, G.A. Somorjai, P. Yang, V.R. Stamenkovic, Science, 343 (2014) 1339-1343.

[130] N. Becknell, Y.J. Kang, C. Chen, J. Resasco, N. Kornienko, J. Guo, N.M. Markovic, G.A. Somorjai, V.R. Stamenkovic, P. Yang, J. Am. Chem. Soc., 137 (2015) 15817-15824.

[131] C.E. Dahmani, M.C. Cadeville, J.M. Sanchez, J.L. Morán-López, Phys. Rev. Lett., 55 (1985)

1208-1211.

[132] H.A. Gasteiger, S.S. Kocha, B. Sompalli, F.T. Wagner, Appl. Catal. B, 56 (2005) 9-35.

[133] X. Huang, Z. Zhao, L. Cao, Y. Chen, E. Zhu, Z. Lin, M. Li, A. Yan, A. Zettl, Y.M. Wang, X. Duan, T. Mueller, Y. Huang, Science, 348 (2015) 1230-1234.

[134] J. Zhang, K. Sasaki, E. Sutter, R.R. Adzic, Science, 315 (2007) 220-222.

[135] C. Wang, D. van der Vliet, K.L. More, N.J. Zaluzec, S. Peng, S.H. Sun, H. Daimon, G.F. Wang, J. Greeley, J. Pearson, A.P. Paulikas, G. Karapetrov, D. Strmcnik, N.M. Markovic, V.R.

Stamenkovic, Nano Lett., 11 (2011) 919-926. 
[136] Y.J. Kang, J. Snyder, M. Chi, D. Li, K.L. More, N.M. Markovic, V.R. Stamenkovic, Nano Lett., 14 (2014) 6361-6367.

[137] P.J. Ferreira, G.J. la O, Y. Shao-Horn, D. Morgan, R. Makharia, S. Kocha, H.A. Gasteiger, J Electrochem. Soc., 152 (2005) A2256-A2271.

[138] K. Sasaki, H. Naohara, Y. Choi, Y. Cai, W.-F. Chen, P. Liu, R.R. Adzic, Nat. Commun., 3 (2012) 1115.

[139] S.I. Choi, S.F. Xie, M.H. Shao, N. Lu, S. Guerrero, J.H. Odell, J. Park, J.G. Wang, M.J. Kim, Y.N. Xia, Chemsuschem, 7 (2014) 1476-1483.

[140] R. Subbaraman, D. Tripkovic, D. Strmcnik, K.-C. Chang, M. Uchimura, A.P. Paulikas, V. Stamenkovic, N.M. Markovic, Science, 334 (2011) 1256-1260.

[141] D. Strmcnik, M. Escudero-Escribano, K. Kodama, R. StamenkovicVojislav, A. Cuesta, N.M. Markovic, Nat. Chem., 2 (2010) 880-885.

[142] B. Genorio, D. Strmcnik, R. Subbaraman, D. Tripkovic, G. Karapetrov, V.R. Stamenkovic, S. Pejovnik, N.M. Markovic, Nat. Mater., 9 (2010) 998-1003.

[143] P.W. Jacobs, F.H. Ribeiro, G.A. Somorjai, S.J. Wind, Catal. Lett., 37 (1996) 131-136.

[144] Y. Yamada, C.K. Tsung, W. Huang, Z.Y. Huo, S.E. Habas, T. Soejima, C.E. Aliaga, G.A.

Somorjai, P.D. Yang, Nat. Chem., 3 (2011) 372-376.

[145] A.G. Dong, J. Chen, P.M. Vora, J.M. Kikkawa, C.B. Murray, Nature, 466 (2010) 474-477.

[146] Y.J. Kang, X. Ye, J. Chen, L. Qi, R.E. Diaz, V. Doan-Nguyen, G. Xing, C.R. Kagan, J. Li, R.J.

Gorte, E.A. Stach, C.B. Murray, J. Am. Chem. Soc., 135 (2013) 1499-1505.

[147] Y.J. Kang, X. Ye, J. Chen, Y. Cai, R.E. Diaz, R.R. Adzic, E.A. Stach, C.B. Murray, J. Am. Chem. Soc., 135 (2013) 42-45.

[148] E.V. Shevchenko, D.V. Talapin, N.A. Kotov, S. O'Brien, C.B. Murray, Nature, 439 (2006) 5559.

[149] N. Danilovic, R. Subbaraman, K.C. Chang, S.H. Chang, Y. Kang, J. Snyder, A.P. Paulikas, D.

Strmcnik, Y.T. Kim, D. Myers, V.R. Stamenkovic, N.M. Markovic, Angew. Chem. Int. Ed., 53 (2014) 14016-14021.

[150] N. Danilovic, R. Subbaraman, K.-C. Chang, S.H. Chang, Y.J. Kang, J. Snyder, A.P. Paulikas, D. Strmcnik, Y.-T. Kim, D. Myers, V.R. Stamenkovic, N.M. Markovic, J. Phys. Chem. Lett., 5 (2014) 2474-2478.

[151] Y. Liang, Y. Li, H. Wang, J. Zhou, J. Wang, T. Regier, H. Dai, Nat. Mater., 10 (2011) 780-786. [152] Z.-S. Wu, S. Yang, Y. Sun, K. Parvez, X. Feng, K. Muellen, J. Am. Chem. Soc., 134 (2012) 9082-9085.

[153] F. Jaouen, E. Proietti, M. Lefevre, R. Chenitz, J.-P. Dodelet, G. Wu, H.T. Chung, C.M. Johnston, P. Zelenay, Energy Environ. Sci., 4 (2011) 114-130.

[154] A. Morozan, B. Jousselme, S. Palacin, Energy Environ. Sci., 4 (2011) 1238-1254.

[155] M. Shao, A. Peles, K. Shoemaker, Nano Lett., 11 (2011) 3714-3719.

[156] P. Mani, R. Srivastava, P. Strasser, J. Power Sources, 196 (2011) 666-673.

[157] G. Wu, P. Zelenay, Acc. Chem. Res., 46 (2013) 1878-1889.

[158] D.-W. Wang, D. Su, Energy Environ. Sci., 7 (2014) 576-591.

[159] Y. Zhao, L. Yang, S. Chen, X. Wang, Y. Ma, Q. Wu, Y. Jiang, W. Qian, Z. Hu, J. Am. Chem.

Soc., 135 (2013) 1201-1204.

[160] H.-W. Liang, W. Wei, Z.-S. Wu, X. Feng, K. Muellen, J. Am. Chem. Soc., 135 (2013) 1600216005.

[161] S. Maldonado, K.J. Stevenson, J. Phys. Chem. B, 109 (2005) 4707-4716.

[162] J. Kibsgaard, Z. Chen, B.N. Reinecke, T.F. Jaramillo, Nat. Mater., 11 (2012) 963-969.

[163] J.S. Spendelow, A. Wieckowski, Phys. Chem. Chem. Phys., 9 (2007) 2654-2675. 
[164] K.J.J. Mayrhofer, B.B. Blizanac, M. Arenz, V.R. Stamenkovic, P.N. Ross, N.M. Markovic, J. Phys. Chem. B, 109 (2005) 14433-14440.

[165] T.F. Jaramillo, K.P. Jorgensen, J. Bonde, J.H. Nielsen, S. Horch, I. Chorkendorff, Science, 317 (2007) 100-102.

[166] J. Greeley, T.F. Jaramillo, J. Bonde, I.B. Chorkendorff, J.K. Norskov, Nat. Mater., 5 (2006) 909-913.

[167] Y. Gorlin, T.F. Jaramillo, J. Am. Chem. Soc., 132 (2010) 13612-13614.

[168] C.C.L. McCrory, S. Jung, J.C. Peters, T.F. Jaramillo, J. Am. Chem. Soc., 135 (2013) 1697716987. 


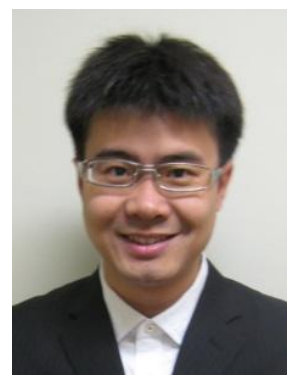

Yijin Kang received his B.S. in Chemistry from Fudan University in 2005 and his Ph.D. in Chemistry from University of Pennsylvania in 2012. He was a postdoctoral fellow at Argonne National Laboratory from 2012 to 2015. He is currently a Professor of Materials Science and Engineering at Institute of Fundamental and Frontier Sciences, University of Electronic Science and Technology of China (UESTC). His research interests include nanomaterials synthesis, selfassembly, and applications in catalysis, energy conversion and storage, biomedicine, and electronics.

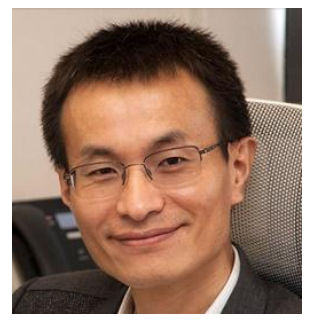

Peidong Yang is a Distinguished Professor in Chemistry at the University of California, Berkeley and member of U.S. National Academy of Sciences. He received PhD degree in chemistry from Harvard University in 1997, and was a postdoctoral fellow at the University of California, Santa Barbara. His research interest includes the synthesis of new classes of materials and nanostructures, with an emphasis on new synthetic approaches and understanding the fundamental issues of structural assembly and growth that enable the rational control of material composition, micro/nano-structure, property and functionality. 


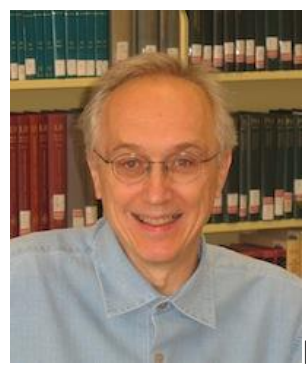

Nenad M. Markovic is an Argonne Distinguished Fellow and group leader at Materials Science Division. He received Ph.D. degree in Chemical Engineering at University of Belgrade in 1978. He was a postdoctoral researcher at the Case Western Reserve University and then he was a group leader at the Institute for Electrochemistry at University of Belgrade. From 1991 to 2005, he was a staff scientist at Lawrence Berkeley National Laboratory and then he joined Argonne National Laboratory in 2005 where he has been pursuing the research aimed to fundamental understanding of the electrified solid-liquid interfaces for energy conversion and storage applications.

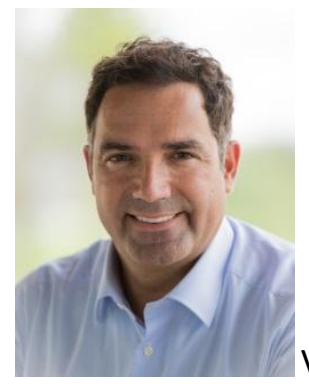

Vojislav R. Stamenkovic is a staff scientist and tech leader at Argonne National Laboratory. He received Ph.D. degree in physical chemistry from University of Belgrade in 2001, after spending three years as a visiting scientist at the University of California at Berkeley. From 2002 to 2006 he was a postdoctoral and staff researcher within the Materials Sciences Division at the Lawrence Berkeley National Laboratory. Since 2006 he is a staff scientist in the Materials Science Division of Argonne National Laboratory. His research interests include materials for energy conversion and storage, electrocatalysis, spectroelectrochemistry and functional bio materials. 


\section{Graphical Abstract}

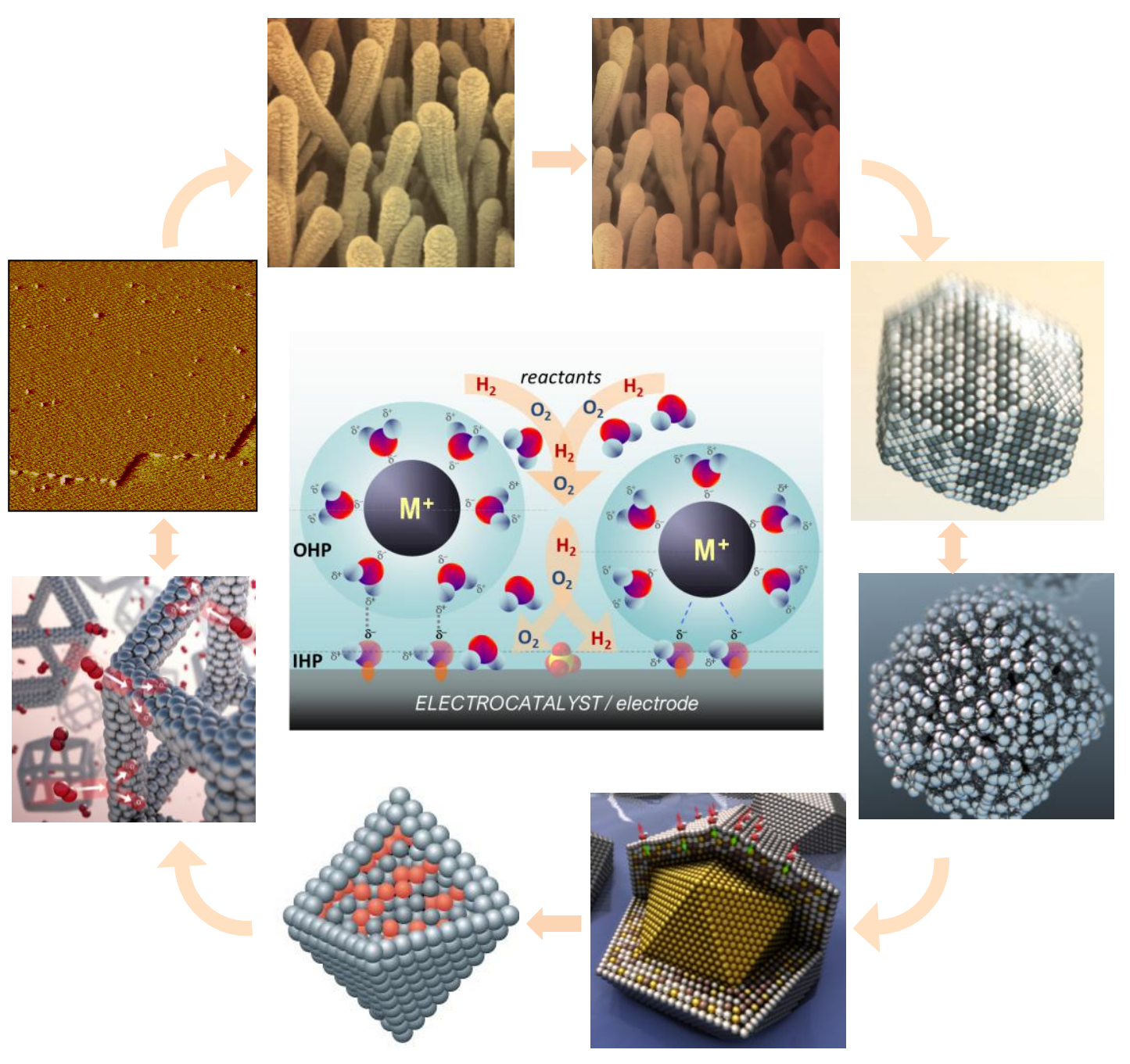

